\title{
EL PROBLEMA \\ DE LAS GENERACIONES ${ }^{1}$
}

\section{Karl Mannheim}

\section{EL ESTADO DEL PROBLEMA}

\section{El planteamiento positivista}

También ante esta cuestión el primer deber del sociólogo es examinar el estado del problema. Tiene que hacerlo con demasiada frecuencia ante el planteamiento de preguntas que se han hecho apátridas, ante problemas a los que todas las ciencias han pagado su óbolo, sin que la problemática se haya abordado unitariamente en su conjunto. Pero no se trata aquí simplemente de ofrecer una «historia dogmática» del problema de las generaciones, sino de bosquejar la «situación interna» del planteamiento de la cuestión (primera parte), para poder asegurar así nuestro propio acceso a la solución de la misma (segunda parte).

El planteamiento de la pregunta sobre el problema de las generaciones ha

1 «Das Problem der Generationen» (1928), Kölner Vierteljabreshefte für Soziologie, VII, 2: 157-185; 3: 309-330. Reproducido en Wissenssoziologie, Kurt H. Wolf (ed.), Neuwied, Luchterhand, 1970 , pp. 509-565. Traducido al inglés como «The Problem of Generations», en Essays on the Sociology of Knowledge, Paul Kecskemeti (ed.), Londres, Routledge and Kegan Paul, 1952, pp. 276-322.-Nota dol traductor: Las páginas de referencia que se indican en el texto para facilitar la comprobación corresponden a la edición alemana editada por Kurt Wolf, que es la más habitualmente citada en la literatura.

\section{Reis}


tomado dos caminos: uno positivista y otro histórico-romántico. Encontramos aquí dos tipos enfrentados de experiencias del mundo, que abordan el tema desde ángulos distintos. El primer camino vio su ideal en la cuantificabilidad de la problemática; buscaba captar cuantitativamente los datos básicos del serhombre. El otro procedía cualitativamente, renunciaba a la luz del día de las matemáticas e interiorizaba el problema. Hablaremos seguidamente del primero.

Al positivista le subyuga el problema de las generaciones, porque ante esta cuestión siente que por fin ha avanzado hasta los hechos básicos del serhombre. Que hay vida y muerte y que se da una duración de la vida limitada y medible, que las generaciones se relevan según intervalos determinados. AI positivista le parece que ahí está presente el marco formal de nuestro destino, dado de tal forma que nos podemos hacer cargo de él y, más aún, de forma que podemos fijarlo numéricamente. En la vida humana todos los demás datos están condicionados. Tan sólo son la expresión de relaciones particulares. Pueden desaparecer y, entonces, desaparece con ellos únicamente una configuración condicionada del ser histórico. En el supuesto de que esos datos básicos cambiasen, el ser-hombre en el sentido que lo conocemos se disiparía - la cultura, la creación, la tradición desaparecerían, o al menos tendrían un aspecto completamente distinto- (509-510).

Ya había jugado Hume con esa idea del cambio de datos. Imaginemos - decía-- que el tipo y la modalidad de sucesión generacional entre los hombres cambia, y que cambia para ser como la de las orugas y las mariposas; supongamos que la vieja generación desaparece de golpe y que la nueva también aparece de una vez. Vayamos ahora más allá e imaginemos al hombre como un ser dotado de un desarrollo espiritual superior en todos los aspectos, de modo que está en condiciones de elegir por sí mismo lo que el propio Hume llamaba forma de gobierno - que era, por cierto, el problema central de su tiempo-. Ante esa alteración en las condiciones existenciales sería posible reconfigurar constantemente la forma del estado - sin guardar miramientos a los predecesores ni a las leyes de éstos- y llevarla a la práctica. Si vemos la necesidad de preservar nuestras formas de gobierno es tan sólo porque la humanidad se presenta - en la configuración efectiva de su sucesión de generaciones - como un continuo flujo, de modo que cada vez que alguien muere ya ha nacido otro para reemplazarle. De acuerdo con esa meditación, el principio de la continuidad política se apoya directamente en ese dato biológico básico de la continuidad de la sucesión de generaciones.

También Comte juega con la idea de ese cambio. Quería iluminar las propiedades y el tempo del progreso - que era a la sazón el mayor problema de su época - y barajaba para ello la posibilidad de que se diesen unos datos básicos distintos en la sucesión de generaciones y en la duración media de la vida de los hombres. Imaginemos — decía - que la duración media de la vida

2 Para la documentación relativa a los planteamientos de Hume y Comte, véase F. Mentre, Le's géncirations sociale's, París, Ed. Bossard, 1920, pp. 179 s. y pp. 66 ss. 
de los individuos se alarga o se acorta: en tal caso, la velocidad, el tempo del progreso, también cambiaría. Al producirse un alargamiento de la duración de la vida del individuo, el tempo del progreso se ralentizaría; mientras que, por el contrario, un acortamiento de aquélla a la mitad o a un cuarto de su medida actual aceleraría el tempo. Esto ocurriría precisamente porque, en el primer caso, los roles de conservación, freno y retardo que desempeña la gente mayor ampliarían su efectividad debido a la mayor duración de la vida de dicha gente; $y$, en el otro caso, porque su desaparición más rápida menguaría dicha efectividad (510-511).

Si hay que entender que es malo un excesivo retardamiento, también es peligrosa una aceleración excesiva de ese tempo, puesto que puede entrañar el peligro del debilitamiento de los contenidos de la vida y del gozo de su vivencia. Sin querer con ello afirmar que nuestro mundo fuera el mejor de los mundos, Comte consideraba, no obstante, que la duración de nuestra vida -y los treinta años de media que dura una generación, lo cual está vinculado con la primera duración - era un correlato necesario de nuestro organismo. Pero iba más allá y consideraba que también la lentitud del progreso de la humanidad está en relación inmediata con esa limitación orgánica. Parece que aquí la explicación del tempo del progreso y de la presencia de fuerzas conservadoras o reformistas se reduce de una forma inmediata al hecho biológico. Es ésta, verdaderamente, una forma de poner el problema a la luz del día. De este modo, todo es poco menos que matemáticamente significativo: todo está claro al analizarlo en partes elementales. La fantasía constructiva del pensador celebra su triunfo. Al combinar libremente los factores ha logrado aprehender los elementos constantes del ser-hombre, y el misterio de la historia queda prácticamente al alcance de nuestra mano.

El racionalismo de los clásicos ha encontrado un sucesor en el racionalismo positivista. El pensamiento francés vuelve por sus fueros y, de hecho, los más valiosos portavoces del problema son, sobre todo, franceses. Comte, Cournot, J. Dromel, Mentré y otros pensadores de fuera de Alemania son positivistas, o han experimentado la influencia positivista: el italiano Ferrari y O. Lorenz -el historiador austríaco- indicaban la dirección de un tiempo en el que la ola del positivismo ceñía a Europa ${ }^{3}$.

Había algo común en el planteamiento que todos ellos hacían del problema (511-512). En el fondo de la cuestión estaba el afán por encontrar una ley general del ritmo de la historia, y de encontrarla a base de la ley biológica de la limitada duración de la vida del hombre y del hecho de la edad y sus etapas. La meta es comprender el cambio formal de las corrientes espirituales y sociales inmediatamente a partir de la esfera biológica; aprehender la configuración del progreso del género humano partiendo del sustrato vital. Y, para lograrlo, todo se simplificará cuanto sea posible: una psicología esquemática se ocupa

A. Cournot, Considcrations, 1872; J. Dromli, La loi des révolutions, les génćrations, les nationalités, les dynasties, les réligions, Didier \& Co., 1962; G. Flerkara, Terria dei periodi politici. Milano, Hoepli, 1974; O. LoRl:Nz, Dic Geschichtswisschsschaft in Hauptrichtungen and Aufgaben kritisch crörtert, parte I, Berlin, 1886; parte II, 1891. 
de establecer que el elemento conservador es la vejez, y de presentar a la juventud únicamente en su aspecto tempestuoso. La historia del espíritu aparece en esa visión como si únicamente se hubieran estudiado las tablas cronológicas. Después de esas simplificaciones parece como si la dificultad del problema tan sólo estribara en calcular el período medio de tiempo que tarda en ser sustituida la generación anterior por la nueva en la vida pública y, principalmente, en encontrar el punto de comienzo natural donde se procede a hacer, en el decurso histórico, un oportuno corte, para poder empezar a contar. La duración de las generaciones se determina de forma diversa según los casos. Algunos fijan la duración del efecto de la generación en quince años (p. ej., Dromel), pero la mayoría de los autores sostiene que dura treinta, fundamentándolo en la siguiente consideración: los treinta primeros son años de formación; sólo al alcanzar esa edad empieza el individuo medio a ser creativo, y cuando llega a los sesenta, el hombre deja la vida pública ${ }^{4}$. Pero lo más difícil es encontrar el origen natural de la sucesión de las generaciones, puesto que, en la sociedad, el nacimiento y la partida se producen continuamente, mientras que los intervalos completos sólo se dan en la familia — si se la toma aisladamente-, que es donde se produce con claridad un tiempo de espera de los hijos hasta que tienen capacidad de casarse.

Tenemos aquí el centro de ese planteamiento de la cuestión; parece que sólo falta aplicarlo a la historia, poner ejemplos. Pero también en esta ocasión la voluntad de establecer distinciones claras profundiza, y aporta varios elementos adicionales al problema.

Es en particular Mentrê —entre cuyos logros está el de haber propuesto la primera revisión histórica de este problema"- quien ha erigido su planteamiento sobre una base sólida (512-513). Este autor analiza la sucesión de la familia humana después de haber tratado —apoyándose en el trabajo de Espinas (Les sociétés animales, París, 1877) - el fenómeno de la generación entre los animales. Sólo después de tratar esa cuestión se atreve a ascender al terreno más complicado, para examinar el problema de las generaciones sociales y espirituales.

También es valiosa la diferenciación del problema que trata de hacer cuando distingue (con Lévy-Bruhl) entre «institutions» y «séries libres». En las «séries»-es decir, en la secuencia de libres agrupaciones de hombres (salo-

+ A nuestro entender, el experimento mejor fundamentado desde el punto de vista científico es el de Rümelin, quien trató de determinar la duración de las generaciones en el conjunto global de la población con un procedimiento meramente estadístico, y con plena independencia con respecto a la problemática de las ciencias del espíritu. Dos fueron en este caso los factores empleados para dicha determinación: el promedio de la edad de casamiento y la media de la duración de la fertilidad matrimonial. De la suma de esos datos (con resultados distintos en los distintos Länder y en los distintos círculos sociales) obtenia la duración de la generación, que resultó ser de treinta y seis años y medio en Alemania y de treinta y cuatro años y medio en Francia. G. RümLlin, «Über den Begriff und die Dauer einer Generation», Reden und Aufsätze, I, Tübingen, 1875.

'F. MinTRE, Le's générations sociales, op. cit.

"En este capítulo trataremos tan sólo sobre los representantes de la teoría de las generaciones que no fueron estudiados por Mentrí. 
nes, grupos literarios, etc.) -- es donde parece más prontamente perceptible la rítmica de las generaciones, y no así en el seno de las instituciones. En éstas, las determinaciones o los productos del trabajo en común establecen, de antemano y con amplio alcance, los hábitos y modos de acción, y, de ese modo, ocultan la novedad que la generación adolescente aporta. Una parte esencial de sus estudios atiende a la pregunta sobre la existencia, en el acontecer histórico, de una esfera predominante _como pudieran ser la política, la ciencia, el derecho, el arte o la economía, etc.- cuyo dominio determinara a todas las demás. La conclusión a la que llega es que en esa rítmica no existe tal predominio univoco de una esfera sobre las demás, porque todas las esferas concretas están insertadas en el flujo de la historia general y se mueven a partir de un centro unitario ${ }^{7}$. No obstante, entiende que la esfera estética es la más apropiada para reflejar como un espejo la transformación global del espíritu. Los principales análisis de la historia de esa esfera en Francia parecieron demostrarle que cada treinta años se habían cumplido transformaciones esenciales.

El libro de Mentré conserva la utilidad propia de una primera visión de conjunto del problema. Pero si uno se atreve a perseverar en el planteamiento del problema con la profundidad que es necesaria, dicho trabajo acaba resultando poco sustancioso a pesar de su magnitud. Por otra parte, hay que decir cuál es la razón que ha llevado a los franceses a interesarse por la etapa juvenil del cambio generacional (513-514). Su interés estriba en que eran testigos directos del repentino sepultamiento de la ola del cosmopolitismo liberal, por una juventud nacionalista en ascensión. El cambio generacional aparecía como una vivencia inmediata y como un problema situado más allá del ámbito de las especialidades científicas, como un problema cuya pista podía seguirse por una vez en la propia realidad vital como una encuesta concreta con sentido observable .

Aunque también haya en Mentré, y de modo significativo, indicios que sugieren que éste trasciende la pura consideración cuantitativa, se puede decir que con él se cierra un primer círculo sobre el problema generacional, cuya disposición básica y cuyo método hemos procurado caracterizar hasta aquí. Ahora bien, el problema admite un tratamiento distinto, ofrece otra posibilidad para ponerlo más al alcance de la vista.

F. Mentré, Les génćrations sociales, op. cit., p. 298.

* Véanse, entre otros, los libros de Aciathon (Les jeunes gens d'aujourd'out, París, Plon Nourrit, 1912), Acieokries (La marcbe montante d'une génération, 1890-1910, 1912), BAINville (Histoire de trots générations) y $G$. VALOIS (D'un siècle à l'autre. Chronique d'unc génération, 1885-1920, París, Nouevelle Librairie Nationale, 1921). Cfr., también, los de E. R. Curtuss (Dic literarischen Wegberiter des neuen Frankreichs, Postdam) y R. PLATZ (Geistige Kämpfe in modernen Frankrcicht, Kempten, 1922), donde también el punto de vista de la generación se considera constantemente. 


\section{EL PIANTEAMIENTO HISTÓRIC()-ROMÁNTICO DEL PROBLEMA}

Si seguimos el rastro del planteamiento del problema en Alemania, nos internamos en una atmósfera completamente distinta. La tesis de que la forma de plantear las cuestiones y los modos de pensar cambian con los países, las épocas y las voluntades políticas dominantes, difícilmente puede encontrar una prueba mejor que la de confrontar las soluciones propuestas para ese problema en los distintos países con las corrientes que dominan en cada uno de ellos. En realidad, tanto Rümelin, al procurar plantear el problema estadísticamente, como $O$. Lorenz, que buscó la solución en la investigación de las genealogías, pagaron sustancialmente el tributo que correspondía al positivismo de la época. Pero el planteamiento de la cuestión adquirió un semblante específicamente «alemán» cuando Dilthey se molestó por su aclaración. Cada uno de los impulsos y tradiciones que habían estado vivos en el romanticismo y la escuela histórica reverdecieron en Dilthey. En él se manifiestan súbitamente y con una configuración renovada cada uno de los planteamientos y categorías que en su día fundamentaron, en Alemania, las ciencias del espíritu precisamente sobre esa base histórico-romántica (514-515).

Las corrientes de pensamiento dominantes que imperan en ambos países durante la última época se corresponden plenamente con sus estructuras históricas y políticas.

En Francia prevaleció el pensamiento positivista, que procedía directamente de la tradición de la Ilustración. Además de dominar las ciencias de la naturaleza, sirvió también de fundamento para las del espíritu. Lo sustentaron las fuerzas de oposición, pero se abrió camino, a la vez, en el conservadurismo y en el tradicionalismo. La situación general fue completamente distinta en Alemania, donde los románticos - movidos por impulsos conservadores- y el historicismo siempre tuvieron la sartén por el mango. En este caso, sólo las ciencias de la naturaleza pudieron constituirse ampliamente bajo el signo del positivismo. Las ciencias del espíritu se establecieron de acuerdo con el modelo histórico-romántico, y el positivismo sólo obtuvo un éxito esporádico, siendo sostenido esencialmente por las corrientes de oposición.

Bajo el signo de esas antítesis dominantes - que no debieran, sin embargo, ser exageradas y exprimidas hasta la última gota - se produce poco menos que un retorcimiento de cada una de las categorías lógicas del pensamiento. De modo que el problema de las generaciones también aparece como una batalla más dentro de esa guerra de vasto alcance. Si se aíslan de esa conexión principal, esa distinción y esa diversidad que predominan entre el planteamiento positivista francés y el planteamiento romántico alemán, en lo que se refiere a la problemática de la generación, no pueden entenderse en absoluto.

Para los liberales franceses, que son positivistas en el sentido ideal-típico que hemos mencionado, el problema de las generaciones es casi siempre una prueba de la concepción rectilínea del progreso.

Ese pensamiento, desarrollado por los impulsos de los liberales modernos, ha operado desde el principio con un concepto del tiempo externalizado y 
mecanicista, procurando hallar en el tiempo cuantitativo y mensurable un patrón apto para medir el progreso lineal. Desde esa perspectiva, también la sucesión de generaciones aparece, ante todo, como un acontecimiento que, más que quebrantar el carácter rectilíneo de la sucesión del tiempo, la articula (515-516). En lo que respecta al cambio generacional, lo más importante sigue siendo su consideración como el factor esencial que impulsa el progreso.

Pero es precisamente esta concepción del progreso la que se desmonta, fase por fase, cuando el pensamiento histórico-romántico alemán - recogiendo el impulso del punto de vista conservador - se esfuerza directamente en encontrar en el problema generacional una contraprueba frente a la linealidad del flujo temporal de la historia". De esta manera, el problema generacional se transforma en el problema de la existencia de un tiempo interior no mensurable y que sólo se puede comprender como algo puramente cualitativo.

Lo que es relativamente novedoso en Dilthey es, justamente, la contraposición entre la mensurabilidad cuantitativa y la comprensibilidad exclusivamente cualitativa del tiempo interior de la vivencia. Según su propia confesión, Dilthey se interesó por el problema generacional preferentemente por la utilidad que podía tener para un adecuado acercamiento al curso de los movimientos espirituales. Gracias a la idea de unidad de la generación, el habitual armazón empleado para estudiar el transcurso de los movimientos espirituales -que venía siendo puramente externo: basado únicamente en horas, meses, años y siglos - podía ser reemplazado «por un concepto que mide desde dentro». Las unidades generacionales posibilitarían, incluso, una medición intuitiva y vivencial de los movimientos espirituales ${ }^{10}$.

Lo que en segundo lugar averigua Dilthey sobre el fenómeno de la generación es que no sólo es su sucesión lo que cobra un sentido más profundo que el meramente cronológico, sino también la contemporaneidad. Los individuos que crecen como contemporáneos experimentan - tanto en los años de gran receptividad como después - las mismas influencias directrices de la cultura intelectual que les moldea y de la situación político-social. Constituyen una generación, una contemporaneidad, porque esas influencias son unitarias. Se produce así un vuelco: se pasa a considerar que, en lugar de ser un simple dato cronológico, la contemporaneidad significa, en la historia del espíritu, la existencia de influencias similares. $Y$ es precísamente mediante ese vuelco como el planteamiento de la cuestión se escapa de un plano por el que tendía a convertirse en una suerte de aritmética mística, y pasa al dominio de esa desnuda temporalidad interior que se puede captar por medio de la comprensión (516-517).

"Sobre la vivencia conservadora del tiempo, cfr. K. MANnflam, «Das Konservative Denken», Arcbiv für Sozial Wissenschaft und Sozialpolitik (1927), 57, 1, pp. 68-142; 57, 2. pp. 470-495. Frente a la concepción del progreso como idea de conjunto de la historia, vid., v. g., W. Pinder, Das problem der Generationen in der Kuntgeschicte Europas, Berlín, 1926, p. 138.

${ }^{11}$ Cfr. W. DiLtrily, «Über das Studium der Geschichte der Wischenschaften vom Menschen, der Gessellschaft und der Staat» (1875), Gesammelte Schreiften, V, pp. 36 ss. 
De un simple problema de contabilidad matemática nace un problema cualitativo, que sólo es vivencial: la distancia de la generación se transforma en tiempo interior vivenciable, y la contemporaneidad de la generación en un ser interior idénticamente determinado.

Desde aquí, sólo hay un paso hasta el fenomenólogo Heidegger, quien profundizó concretamente en ese problema de la adhesión cualitativa e intentó determinar ese ser-vinculado como «destino colectivo». «El "destino colectivo" (das Gescbick) no es una conjunción de "destinos individuales" (das Schicksal), como tampoco cabe concebir el "ser uno con otro" como un venir a estar juntos algunos sujetos. Los "destinos individuales" están ya trazados individualmente en el "ser uno con otro" en el mismo mundo y en la misma situación de clausura ante determinadas posibilidades. El poder del "destino colectivo" se libera ante todo en la comunicación y en la lucha. Lo que constituye el propio acontecer cabal del "ser ahî" es el "destino común" individualmente destinado del "ser ahí" en y junto a su "generación"»".

El planteamiento del problema que propone el historiador del arte Pinder crece de las mismas raíces que el concepto cualitativo de tiempo que ya encontramos anteriormente al citar a Dilthey ${ }^{12}$. Es agradable reconocer en Dilthey esa suerte de moderación con que supo hacer valer tan sólo las verdaderas posibilidades que ofrecía en el plano cualitativo la irrupción de los románticos. Incluso entendió también que había que aprender del positivismo. Pinder, por el contrario, cometió todas las locuras del Romanticismo; profundizó muchísimo, pero no comprendió cómo se podía uno salvar del desbocamiento de los románticos. Lo que le interesaba, ante todo, del fenómeno generacional era la «no contemporaneidad de los contemporáneos». Varias generaciones viven en el mismo tiempo cronológico. Pero como el único tiempo verdadero es el tiempo vivencial, se puede decir propiamente que todas viven en un tiempo interior que en lo cualitativo es plenamente diferente a los otros. «Cada uno vive con gente de su edad y con gente de edades distintas en una plenitud de posibilidades contemporáneas. Para cada uno el mismo tiempo es un tiempo distinto; a saber: una época distinta y propia de él, que sólo comparte con sus coetáneos» ${ }^{13}$ (517-518).

Por eso, cada momento de tiempo es propiamente un ámbito temporal que tiene varias dimensiones, puesto que siempre se accede a él desde la diversidad de los despliegues de cada uno de los estratos generacionales particulares que están presentes ${ }^{1+}$. Por eso, también el pensamiento del tiempo tiene que

"M. HEndgcier, «Sein und Zeit», Jabrbuch für Philosophie und phänomenologische Forschung, Halle, 1927, pp. 384 s.-Nota del traductor: Las comillas de la palabra «generación» son de Heidegger, quien remite, para la aclaración de este concepto, al texto de W. Dilthey de 1885 que el propio Mannheim cita y recoge en la bibliografía. Puede comprobarse el texto en la versión española de José Gaos, que no empleamos en este caso porque entendemos que oscurece innecesariamente el sentido ( $E l$ ser y el tiempo, México, FCE, 1980 [3."], p. 415).

${ }_{12}$ W. Pinder, Das problem der Generationen in der Kuntgeschichte Europas, op. cit., especialmente cap. 7 .

"Ibiden, p. 21. La cursiva es de Pinder.

it Cfr. ibidem, p. 20. 
organizarse, a la fuerza, polifónicamente - por emplear una metáfora musical de Pinder--; en cada punto de tiempo hay que escuchar las propias voces de las generaciones particulares que llegan por sí mismas constantemente a cada punto.

Pero hay que mencionar un segundo pensamiento de este autor. Según él, cada generación construye desde sí misma una «entelequia» propia, y por medio de ella llega propiamente a constituirse como una unidad cualitativa. El vínculo que unifica la generación no era todavía plenamente comprensible como cualidad en Dilthey, puesto que éste entendía la unidad interior de una generación como comunidad de influjo espiritual y social. Así como en este punto Heidegger recurrió a la ayuda del concepto de un «destino colectivo», que constituiría de antemano la unidad, Pinder empleó el concepto de entelequia, procedente de la tradición moderna de la historia del arte.

Según él, la entelequia de una generación es la expresión de la unidad de su «meta íntima», la expresión de su nativo sentimiento de la vida y del mundo. Si se la considera desde la tradición de la historia del arte, resulta que la entelequia generacional es una transferencia del concepto de Riegl de «voluntad artística» ${ }^{15}$, desde el ámbito fenoménico de la unidad de estilo a la unidad generacional. Pero es que el propio concepto de voluntad artística de Riegl había supuesto, a su vez, un rejuvenecimiento y una fructificación de las tendencias morfológicas — un tanto traducidas al positivismo- que ya estaban esbozadas en el concepto histórico de «espíritu del pueblo» (Volkgeist). Hasta entonces se había trabajado principalmente con la unidad «espíritu del tiempo» (Zeitgeist) ${ }^{16}$. Pues bien, esa unidad se interpreta ahora - según otra expresión de Pinder que da muestra de su preferencia por la analogía musical-- como un falso acorde: el de la coincidencia vertical de varias notas sueltas que pertenecen prioritariamente a los sistemas horizontales (aquí hay que tener a la vista primordialmente a las entelequias generacionales) de una fuga ${ }^{17}$ (518-519). Es así como las entelequias de una generación también sirven

${ }^{15}$ Para esto, cfr. K. MANNinim, «Beiträge zur Theorie der WeltanschauungsInterpretation», Jabrbucb für Kunstgeschicbte, I (Wien, 1923). Publicado también en la serie «Kuntstgeschichtliche Einzeldarstellungen», II, compilación del «Kunsthis. Institut des Bundesdenkmalamtes», Wien, 1923, pp. 38 ss.

16 Nota del traductor: Como puede verse en este pasaje, resulta en este caso difícil mantener, sin una innecesaria pérdida de matices, la versión del término Zeitgeist que emplean, entre otros, Francisco Ayala, Laín Entralgo o Julián Marías, que lo traducen como «espíritu de la época», a pesar de seguir la estela de Ortega, que hablaba del «espíritu del tiempo» (o del «mundo vigente»), entendiendo por tal «las convicciones comunes a todos los hombres que conviven en una época». Tanto en este como en algún otro lugar del ensayo, Mannheim emplea también - discriminadamente y en paralelo con la de Geistzeit - la expresión correlativa «espíritu de la época» («Der Geist einer Epoche», dice Mannheim). Cfr. F. Ayala, Tratado de sociología, Madrid, Espasa-Calpe, 1984 (v. o., 1947), pp. 242 ss.; P. Lain Entralcio, Las generaciones en la bistoria, Madrid, Instituto de Estudios Políticos, 1945, passim; J. MARías, El método bistórico de las generaciones, Madrid, Revista de Occidente, 1949, passim. En cuanto a la cita de Ortega que hemos hecho aquí, vid. J. Ortecia y Gasset, En torno a Galileo, en Obras completas, V, Madrid, Alianza, 1983, p. 43.

${ }^{1}$ W. PINIER, Das problem der Generationen in der Kuntgeschichte Europas, op. cit., p. 98. 
en este caso para destruir la sobreacentuada unidad del tiempo (el espíritu del tiempo, el espíritu de una época). La unidad de una época no tiene impulso dinamizador alguno, no cuenta con ningún principio formativo unitario; carece, por lo tanto, de entelequia. Su unidad consiste, a lo sumo, en una situación de afinidad en cuando a los medios que un mismo momento de tiempo pone a disposición de la generación para las distintas tareas. Existen, entonces, «colores del tiempo»; «verdaderamente existen - dirá Pinder- pero existen de alguna manera como barnices que lucen débilmente sobre los varios colores de los grupos de edad y de la generación $)^{18}$.

Si con esta negación de la existencia de una entelequia correspondiente a la unidad de una época se niega esencialmente dicha unidad, y el concepto de espíritu del tiempo se relativiza y queda destruido, no ocurre lo mismo, en cambio, con las restantes unidades con las que se cuida de trabajar la historia, que se mantienen en su sitio. Según Pinder, aparte de la entelequia de la generación hay entelequias del arte, del lenguaje, del estilo, de las naciones y de las tribus, pero también existe una entelequia de lo europeo y, por último, también hay entelequias de las individualidades.

¿Cómo se configura, según Pinder, el acontecer histórico? Pues mediante el juego de conjunto de factores constantes y de factores temporales. El ámbito cultural, la nación, la tribu, la familia, la individualidad, el tipo, son los factores constantes. Mientras que las entelequias ya mencionadas serían los factores temporales. «Se sostiene la prioridad del crecimiento sobre las experiencias ("influencias", "relaciones"). Se sostiene también que la vida de la historia del arte deriva de la cooperación de las entelequias determinantes, que nacen en los misteriosos procesos naturales, con las fricciones, influencias y relaciones (esencialmente autocomprensibles en todo caso) que se experimentan en el curso del desarrollo efectivo de esas entelequias» ${ }^{19}$. Pero salta inmediatamente a la vista que aquí el factor social no aparece - ni siquiera remotamente- en ninguna de las series de factores enumerados.

Esa corriente romántica alemana oculta completamente el hecho de que, entre las esferas natural y espiritual, se sitúa el plano de las fuerzas sociales formativas (519-520). O bien se es plenamente espiritualista, haciendo que todo proceda de las entelequias (que ciertamente existen), o, por el contrario, se siente la obligación de aportar algo de realismo al asunto y, entonces, se afirma lo inmediatamente vital - la raza, la generación, que ciertamente también existen- y la causación de las potencias del espíritu a partir de «los misteriosos procesos naturales». Sin duda, existen todavía misterios en el mundo; pero hay que dejar que se hagan valer en su propio ámbito, y no allí donde las aglomeraciones de fuerzas pueden todavía entenderse en gran parte desde el acontecer social. Porque, ciertamente, las relaciones sociales en las que por de pronto los hombres se encuentran tienen también, en sus agrupaciones, una fuerza de configuración; es en ellas donde los hombres se enconan

is Ibid'm, pp. 159 s.

"Ibidan, p. 154. Los paréntesis son de Pinder. 
entre sí y donde sus luchas reales producen entelequias, y es desde ellas desde donde la religión, el arte, etc., influyen y modelan intensamente. Pero tal vez sea provechoso preguntar si se trata en este caso únicamente de «fricciones», «influencias» y «relaciones», o si es que esos factores irradian también fuerza creadora, poder constructivo, entelequia social. Esas energías que fluyen a partir del «ser con otro» y del «ser contra otro» sociales, ¿no mediarán acaso entre entelequias como las del arte, el estilo, la generación, etc., que, de lo contrario, sólo convendrían y se entrecruzarían entre sí casualmente? Si las cosas no se consideran en este sentido, y se establece una relación directa entre las formas superiores de expresión de lo espiritual y las esferas vitales, sin mediación histórico-social alguna, las generaciones decisivas son «jugadas de la naturaleza» ${ }^{211}$, y «uno se siente poco menos que procurando ver cómo alborea, a partir del problema del momento del nacimiento, el aún más misterioso y difícil problema del momento de la muerte» ${ }^{21}$. Cuánto más sobria, cuánto más verdaderamente conveniente para el afán de investigación es, en cambio, la sentencia de Dilthey, que, anticipándose de algún modo a tales especulaciones, dice así: «Aunque lo más natural parece ser la aceptación de que en todo punto, tanto en lo que respecta a la magnitud de las disposiciones como a la participación en las mismas, se dan las mismas posibilidades en cada generación - bajo condiciones en todo iguales de capacidad nacional-, sin embargo, tanto la participación como la intensidad de los resultados se explicarán según esos dos grupos de condiciones» ${ }^{22}$ (520-521).

Son valiosos - francamente geniales - los pensamientos de Pinder sobre la «no contemporaneidad de los contemporáneos» y sobre las entelequias; dos pensamientos procedentes del planteamiento histórico-romántico que están fuera del alcance del positivismo. Pero al quedar a merced de las formas de pensar analógicas, sus argumentos se hacen peligrosos y amenazan toda cientificidad. Ese modo de pensar, que en realidad procede de las especulaciones filosófico-naturales del Renacimiento, fue reavivado y acrecido hasta niveles grotescos por los románticos. Actualmente es Pinder quien lo pone en uso cada vez que infiere el ritmo biológico del mundo. Y, a partir de ahí, también él procura fijar en el acontecer histórico intervalos que se puedan comprobar cuantitativamente (aunque los trate con algo más de elasticidad de lo que es habitual), trata de encontrar en el curso de la historia estratos de nacimiento decisivos, con la ayuda de esa fórmula mágica de las generaciones. Joel ${ }^{23}$, el otrora provechoso investigador, procede aún de modo más constructivo. Ante sus más recientes argumentos sobre el ritmo secular de la historia, uno siente como si realmente estuviera recordando las especulaciones de los románticos.

Es un error pensar, como hace la mayor parte de los investigadores, que

20 Ibiden, p. 30.

2) Ibiden, p. 60 .

22 Esas condiciones son la situación cultural y las circunstancias sociales y políticas. W. Diltiey, «Über das Studium der Geschichte...», op. cit., p. 38.

${ }^{3} \mathrm{~K}$. Joll, «Der sekuläre Rhythmus der Geschichte», Jabrbuch für Soziologie, 1 (1925), Karlsruhe. 
sólo se tiene un auténtico problema generacional cuando se es capaz de ofrecer un ritmo de las generaciones con intervalos fijables para todos los casos. Pero, aun cuando haya que señalar que la teoría de los intervalos no se puede probar, el problema generacional sigue siendo un problema fecundo que hay que investigar.

Aunque no lo sepamos, quizá haya también un ritmo secular en la historia y tal vez un día el hombre llegue a conocerlo. Pero debemos resistirnos a llegar a saberlo por un camino de especulación imaginativa — de forma muy especial cuando esa especulación biológica o espiritualmente fundada es tan sólo una salida para evitar la investigación, que es más cercana e investigable, de la textura que trasluce el acontecer social y de su efecto sobre el fenómeno de las generaciones- (521-522). El ritmo biológico se produce en el elemento del acontecer social; cuando se pasan completamente por alto esos estratos de formación y se intenta comprender todo directamente desde lo vital, se pierden, en el propio modo de plantear la solución del problema, todas las semillas fructíferas que tan favorable y prometedoramente estaban presentes al plantear la cuestión ${ }^{24}$.

\section{EL PROBLEMA SOCIOLOGICO DE LAS GENERACIONES}

El de las generaciones es un problema importante que hay que tomar en serio. Es una de las guías indispensables para el conocimiento de la estructura de los movimientos sociales y espirituales. Su significado práctico se ve inmediatamente cuando se intenta comprender con exactitud la acelerada transformación de los fenómenos del presente inmediato. Sería una lástima que esta transformación fuera encubierta por el empleo de métodos extracientíficos, sin que haya lugar para una mayor investigación sobre la duración.

A partir del examen que hemos hecho del estado actual de la cuestión, queda completamente claro que falta unidad en el planteamiento del problema. Las disciplinas de las ciencias sociales y de las ciencias del espíritu de los distintos países punteros sólo ocasionalmente toman en cuenta los resultados de las demás. Esto ha ocurrido de forma muy especial en la investigación alemana sobre el problema de las generaciones, que no ha tenido en cuenta para nada la situación exterior. El hecho de que el problema lo hayan abordado siempre diversas disciplinas aisladas ha provocado una situación en la que, a lo sumo, se puede hablar de acometidas interesantes y de contribuciones a la solución general, pero donde no es posible hablar de un planteamiento claro del problema ni de una investigación que sea consciente de su propósito (522-523).

${ }^{2+}$ O. LoREnz (Die Geschichtswissensschaft, op. cit.) intentó sustituir la unidad secular por el criterio más sano de la unidad de tres generaciones. En su historia de la literatura, W. Scherer (Geschicbte der deutschen Literatur, 3." ed., Berlín, 1885, pp. 18 ss.) subraya un ritmo de seiscientos años. Sobre los resultados de la investigación de los historiadores modernos de la literatura, como Kummer y Petersen y, también, de L. von Wiese, nos ocuparemos en la otra parte de esta investigación. 
Hay, ciertamente, gran atractivo y riqueza en la multiplicidad de puntos de partida que proceden tanto de la variedad de tradiciones de pensamiento de las naciones particulares como de las propias modalidades de pensamiento de las distintas ciencias concretas; un problema tan vasto como éste sólo puede resolverse con una adecuada cooperación de las diversas disciplinas y naciones. Pero una cooperación tiene que ser planificada desde algún sitio y tener una cohesión interna establecida desde un centro de organización. El estado actual del problema generacional resulta así ser un ejemplo eminente de la carencia de plan en las ciencias sociales y en las del espíritu, donde ocurre que cada una empieza siempre de nuevo (lo cual es hasta cierto punto fructífero y necesario), y donde sólo muy de vez en cuando se plantea la pregunta sobre si esos variados puntos de partida no pueden considerarse como elementos de un conjunto problemático unitario, a la vista del cual se pudiera deliberar acerca del papel y la participación de las disciplinas particulares.

Aunque tampoco sea deseable una organización excesiva de las ciencias del espíritu y de las ciencias sociales, es necesario meditar, al menos, si acaso no hay siempre una disciplina que - habida cuenta de la especificidad propia de la cuestión- pudiera proporcionar ese centro de organización. En cuanto al problema de la generación, no cabe duda de que es la sociología la que ha puesto de relieve su planteamiento. En este caso, parece ser cometido directo de la sociología formal proporcionar tanto los estados de cosas más elementales como los fundamentales sobre el fenómeno de la generación. Sin embargo, dentro de la propia sociología formal este problema se sitúa en el linde entre la investigación dinámica y la estática. Si bien hasta ahora la sociología formal había investigado casi siempre la existencia de grupos humanos exclusivamente desde la perspectiva estática, dicho problema parece pertenecer a un conjunto de cuestionamientos que han venido precisamente a poner de relieve tanto las fuerzas causales que fundamentan el dinamismo del acontecer social como también el propio ordenamiento de la eficiencia de sus componentes dinámicos. De este modo, tendríamos precisamente aquí el punto de transición desde una pura sociología formal estática a una sociología formal dinámica, y desde ésta a una sociología histórica aplicada; estaríamos ante el punto de confluencia de las tres disciplinas que, juntas, pueden constituir, por primera vez, el campo completo de la investigación sociológica (523-524).

A continuación habrá que poner de relieve los estados de cosas más elementales que conciernen al fenómeno generacional a la luz de la sociología formal, sin cuya clarificación la investigación histórica no puede añadir nada en esa dirección. Pero, a la vez, emplearemos todos los conocimientos que hasta ahora se han acumulado y que han demostrado ser conformes a la realidad, mientras que silenciaremos aquellos que no nos parecen suficientemente fundados. 
1. El gRUPO CONCRETO Y LA POSICIÓN SOCIAL

Si queremos presentar el fenómeno de la conexión generacional (Generationszusammenbang) a partir de sus estructuras fundamentales, lo que se impone es la aclaración del específico «ser con otro» de los individuos adheridos a la unidad generacional.

De entrada, la unidad de una generación no consiste en absoluto en una adhesión que aspire al desarrollo de grupos concretos, aunque ocasionalmente pueda ocurrir que el hecho de la unidad de la generación se convierta en la base para establecer la unidad consciente en el proceso de formación de grupos más concretos (como la Jugendbewegung —el «Movimiento de la Juventud»- en la época moderna $)^{25}$. Cuando esto ocurre, esas formaciones son por lo general alianzas y únicamente se forman a través de algo de carácter específico. Pues bien, en el caso concreto que consideramos, ese algo específico no tiene inicialmente contenido objetivo alguno, pues lo que se convierte en la base para la formación de grupos concretos es la propia conexión generacional que se torna consciente.

A partir de esos casos especiales -en los que la conexión generacional puede convertirse en el origen del desarrollo de grupos concretos- vemos que, de entrada, se puede plantear la conexión generacional precisamente como una mera conexión, en contraposición con el desarrollo de grupos concretos.

Ejemplos de tales desarrollos de grupos concretos son las mancomunidades, la familia, la tribu, las comunidades de credo, etc. Todas esas formas de grupos concretos se caracterizan porque los individuos que están agregados a ellas constituyen, además, in concreto un grupo (524-525). La unidad de los grupos puede estar fundamentada esencialmente en los lazos - previos, vitales, existenciales - de la «proximidad», o bien puede ser fundada - de forma consciente y querida - por la «voluntad de arbitrio»*. El primero de esos dos

25 En este contexto habría que destacar, entre otras, la distinción estructural, tan exactamente perfilada por $K$. Schurtz, entre los grupos de edad y los lazos interhumanos que se dan entre los llamados «primitivos», por una parte, y los movimientos generacionales modernos, por otra.

* Nota del traductor: La expresión «voluntad de arbitrio» corresponde a la palabra Kürwille, una expresión poco usual, que Mannheim toma probablemente de la obra de Ferdinand Tönnies, Gemeinschaft und Gesellscbaft. Ya Lissarrague la tradujo como «voluntad de arbitrio» o «voluntad arbitrada». Se trata precisamente del tipo de voluntad humana que funda la Gesellschaft, establecida, como precisaba Lissarrague glosando a Tönnies, «no sólo por decisión libre, sino libérrima, externa, calculada, fácilmente cambiante». Por contra, los sujetos estarian en Gemeinschaft por voluntad esencial (Wesenswille).

Arthur Mitzmann aclara al respecto que Tönnies empleó en la primera versión de su obra capital la expresión más común Willkür (que se emplea usualmente para designar la «arbitrariedad») y observa que Tönnies no fue plenamente claro en la diferenciación de esas dos voluntades. Parsons estableció la diferencia con mayor limpieza en The Structure of Social Action. Cf. F. Tönnies, Comunidad y asociación, Barcelona, Peninsula, 1979 (v. o.: Gemeinschaft und Gesellschaft: Abhandlung des Communismus und Socialismus als empirischer Culturformen, Leipzig, Fues's Verlag, 1887, 2." ed.: Gemeinschaft und Gesellschaft. Grudbegriffe der reinen Soziologie, 1935), los conceptos Kürwille y Wesenswille' están tratados en las pp. 88 y 107 de la segunda edición, que es la matriz de las numerosas reimpresiones posteriores del libro; A. Mitzmann, «Toennies and German Society», en 
tipos de unidad corresponde a todas las «formaciones comunitarias» como la familia, la tribu, etc., y el último a las «formaciones asociativas».

En cuanto a la conexión generacional considerada en sí misma, no cabe caracterizarla como un grupo concreto en el sentido en que lo es la comunidad, donde el saber unos de otros in concreto es condición previa, y cuya descomposición anímico-espiritual tiene lugar cuando se diluye la proximidad exterior. Pero la conexión generacional tampoco es semejante a las formaciones asociativas - como, por ejemplo, las mancomunidades-, donde lo característico es la fundación consciente y querida, la adhesión a estatutos y la revocabilidad, las cuales tienen, en este caso, la función de reemplazar a la mera proximidad exterior y a la vinculación que se da simplemente de manera vital.

Hablamos de «grupo concreto» cuando existen lazos que unen a los individuos a un grupo, ya sea que estos lazos hayan crecido orgánicamente o que hayan sido establecidos. Pues bien, la conexión generacional es un ser los individuos unos con otros en el que se está vinculado por algo; pero de esta adhesión no se deriva aún, de forma inmediata, ningún grupo concreto. Con todo, la conexión generacional es un fenómeno social cuyas propiedades tienen que ser descritas y comprendidas.

Tal vez pueda ayudar en la aclaración que mencionemos una categoría social completamente distinta en apariencia y que muestra una semejanza con la conexión generacional en determinados hechos estructurales básicos, aunque en cuanto al contenido es en realidad diametralmente opuesta a ella. Estamos pensando en el fenómeno de la situación de clase. En su sentido más amplio, se puede entender por situación-de clase la afinidad de posición que están destinados a tener determinados irrdividuos dentro de la contextura económica y de poder de su respectiva sociedad. Uno es proletario, empresario, rentista, etc., y lo es porque experimenta siempre el gravoso peso de una posición específica en la contextura de la sociedad (ya sea en forma de presión social o de oportunidad social). Esa posición en los ámbitos sociales no es como la pertenencia a una asociación, que puede revocarse mediante un acto intelectual y voluntario (525-526); pero por ese hecho tampoco se encuentra uno vinculado en el mismo sentido en que lo está en la comunidad, donde, por destino vital, uno está vinculado con todos los hilos de su existencia a un grupo concreto.

La posición sólo se puede abandonar por ascenso o por descenso, bien sean éstos individuales o colectivos, y es indiferente, de entrada, si esto ocurre por propio mérito, por el propio esfuerzo o debido a la coyuntura social o por mera casualidad.

La pertenencia a una «asociación» se extingue al revocarse la relación; los vínculos comunitarios se acaban cuando las relaciones espirituales-anímicas se

Journal of the History of Ideas, 32 (1971), 507-524, pp. 507-508; S. Lissarrague, Bosquejo de la teoria social, Madrid, Inmansa, 1966, pp. 155-156, 162; la cita es de la p. 156, y T. PArsons, La estructura de la acción social, I-II, Madrid, Guadarrama, 1968, tomo II, pp. 836-846 (v. o.: 1937). 
disuelven en nosotros mismos, o en los demás miembros del grupo; la anterior situación de clase pierde relevancia para nosotros cuando la reconfiguramos al cambiar nuestra posición económica y de poder.

Uno se encuentra en una situación de clase, y es secundario si lo sabe o no, si se suma a ella o si oculta ante sí mismo que está agregado a ella.

No es de ningún modo cierto que una situación de clase posea siempre conciencia de clase, aunque en determinadas condiciones sociales ésta pueda surgir de aquélla, conferirle un cuño especial y posibilitar la configuración del fenómeno de la «clase que se autoconstituye» a partir de la mera situación de clase ${ }^{26}$. Pero lo que aquí nos interesa, en estrecha conexión con las formaciones ya analizadas, es únicamente el fenómeno de la posición (Lagerung) en los ámbitos sociales. Frente a las unidades de los grupos concretos se da el fenómeno del parecido que los hombres tienen por su posición en los ámbitos sociales - se trata de un momento donde la situación de clase y la conexión generacional se asemejan.

En este primer paso del análisis hemos tomado el fenómeno de la posición contraponiéndolo a la formación de «grupos concretos». Y es en esa perspectiva donde tan claro parece, de entrada, que la conexión generacional descansa en el parecido que hay entre los individuos agregados a una generación por su posición en los ámbitos sociales (526-527).

\section{La DELIMITACIÓN DEL PlanteAmiENTO BIOLÓgICO Y SOCIOLÓgiCO EN EL ÁMBITO DE LOS FENÓMENOS GENERACIONALES}

La afinidad de posición que pueda existir en un ámbito social sólo puede determinarse indicando la contextura concreta en la cual, y por medio de la cual, uno se encuentra situado de modo parecido dentro de la vida sociohistórica. La situación de clase se fundamentaba en la correlativa existencia, en la sociedad, de una estructura económica y de poder que está en transformación. Por su parte, la posición generacional (die Generationslagerung) se fundamenta en la existencia del ritmo biológico en el «ser ahí» del hombre: en los hechos de la vida y de la muerte y en el hecho de la edad. Uno se encuentra en una posición parecida a la de otros en la corriente histórica del acontecer social debido a que pertenece a una generación, a un mismo «año de nacimiento».

Se podría pensar, entonces, que el fenómeno social de la comunidad de pertenencia a una generación se puede comprender y deducir inmediatamente desde las estructuras biológicas. Ese es precisamente el error de todas las

26. La aclaración del nivel de desarrollo y de las condiciones en las que se produce la elevación de la situación de clase a conciencia de clase puede servir de tema para una investigación histórico-sociológica. También puede convertirse en problema históricosociológico el intento de saber cuándo se hacen conscientes de su posición generacional y convierten esa conciencia en la base del «estar-vinculado» las nuevas generaciones. ¿Por qué se eleva a la conciencia la unidad generacional precisamente durante la juventud? Esa es la cuestión que hay que resolver aquí en primer plano. 
teorías naturalistas. Intentan éstas deducir lo sociológico de esos datos naturales, y querrían hacer que el fenómeno social surgiera de esas realidades que, en principio, son meramente antropológicas. Desde la antropología y la biología sólo son comprensibles el hecho de la vida y de la muerte, la limitada duración de la vida y las transformaciones anímicas, espirituales y corporales que se producen con la edad; pero no así la relevancia que cobran esos hechos originarios para el «ser con otro» histórico y social.

El fenómeno sociológico de la conexión generacional se fundamenta en el hecho del ritmo biológico del nacimiento y de la muerte. Estar fundamentado en algo no llega a significar ser deducible de, estar contenido en, ese algo. Un fenómeno que se fundamenta en otro no puede darse ciertamente sin él, pero contiene en sí, en contraposición con el fenómeno que lo fundamenta, un sobreañadido cualitativamente propio y no deducible de aquél (527-528). Si el «ser con otro» de la sociedad de los hombres no se diera, si no se diera una estructura determinada y propia de la sociedad, si no se diera una historia que se apoya en continuidades específicas de cierta clase, no nos enfrentaríamos, entonces, con las formas de conexión generacional que se apoyan en el fenómeno de la posición, sino tan sólo con el nacimiento, el envejecimiento y la muerte. Por lo tanto, el problema sociológico de las generaciones comienza donde se distingue la relevancia sociológica de esos datos previos. Ahí está la primera tarea - para ir más allá de los fenómenos elementales-: comprender la conexión generacional como un tipo específico de posición social.

\section{LA «TENDENCIA INHERENTE» A UNA POSICIÓN}

La situación de clase y la situación generacional (la comunidad de pertenencia a años de nacimiento próximos) tienen algo en común, debido a la posición específica que ocupan en el ámbito sociohistórico los individuos afectados por ellas. Esa característica común consiste en que limitan a los individuos a determinado terreno de juego dentro del acontecer posible y que les sugieren así una modalidad específica de vivencia y pensamiento, una modalidad específica de encajamiento en el proceso histórico. Por lo tanto, una posición de ese tipo elimina, de entrada, un gran número de las modalidades y formas de vivencia, pensamiento, sentimiento y acción que son posibles en general, y delimita determinadas posibilidades circunscritas como terreno de juego de las realizaciones de la individualidad. Pero al fijar esa limitación negativa, no nos hemos hecho cargo de todo. Porque existe, además, en sentido positivo, una tendencia hacia determinados modos de conducta, sentimiento y pensamiento, que es inherente a cada una de esas posiciones, y que los sociólogos pueden captar comprensivamente a partir del poderoso peso de la posición.

Queremos, por eso, hablar de una tendencia inberente a cada posición que puede ser determinada desde la propia posición.

La sociedad se presenta con un aspecto determinado ante una determinada situación de clase, mediante una experiencia que se repite constantemente; 
pero eso ocurre también con los contenidos del sentimiento, del pensamiento y de la vivencia que llenan el ámbito socioespiritual (528-529). Estos no existen «en general», sino que en cada situación de clase están presentes únicamente con un «aspecto» determinado. Es extremadamente probable que los proletarios participen de los bienes culturales de un modo que en su estrato es usual y que sólo participen de determinados bienes culturales. Incluso si considerásemos una espiritualidad tan unitaria y fascinadora como la de la cultura eclesiástica medieval, veríamos que ofrece unos contenidos determinados al clérigo que practica la teología, otros distintos al juez, otros al monje, y así sucesivamente. Pero también donde se ofrecen o son accesibles los mismos contenidos espirituales - y en la medida en que lo son-, el propio modo de acceso a ellos, y también el modo y la manera de cambiarlos, de elaborarlos o de desarrollarlos, están siempre más o menos determinados en una dirección. En estos casos es frecuente decir que los modos de acceso han de determinarse en cada ocasión por medio de las tradiciones específicas del estrato correspondiente. Pero las tradiciones de los círculos de vida y de los estratos sociales no sólo son comprensibles y explicables desde la historia, sino principalmente desde la posición que los estratos en cuestión ocupan en el conjunto del ámbito de juego social. Las tradiciones que empujan en una determinada dirección sólo se mantienen mientras la posición del estrato que las sostiene en los ámbitos sociales permanece igual en todos sus aspectos. La configuración concreta de una actitud o de un contenido dado no resulta de la historia de una determinada tradición, sino que en último término resulta de la historia de la posición con la que aquéllos han nacido y con la que se han solidificado dentro de una tradición.

\section{HeChOS BÁSICOS EN EL ÁMBITO DE LOS FENÓMENOS GENERACIONALES}

De acuerdo con la descripción que hasta ahora hemos hecho, la conexión generacional no es, ante todo, otra cosa que una modalidad específica de posición de igualdad dentro del ámbito histórico-social, debida a la proximidad de los años de nacimiento. Si lo que es propio de la posición de clase se puede determinar estrechamente mediante la caracterización de las condiciones económico-sociales, por su parte, la posición generacional se puede determinar a partir de ciertos momentos vitales — basados en los datos naturales de la mudanza de las generaciones- que sugieren a los individuos afectados por ellos determinadas formas de vivencia y pensamiento (529-530).

Podemos llegar a tener con toda claridad ante los ojos cuáles son exactamente los momentos estructurales que se establecen, en la vida y en la vivencia, mediante el fenómeno de la generación. Basta para ello que - con propósito experimental- nos preguntemos, en nuestro fuero interno, cómo aparecería la vida social humana si una generación viviese eternamente y no tuviese lugar ninguna sucesión generacional más. Frente a la sociedad humana 
utópicamente construida que concebiríamos de ese modo, la nuestra se caracteriza ${ }^{27}$ :

a) por la constante irrupción de nuevos portadores de cultura;

b) por la salida de los anteriores portadores de cultura;

c) por el hecho de que los portadores de cultura de una conexión generacional concreta sólo participan en un período limitado del proceso histórico;

d) por la necesidad de la tradición - transmisión- constante de los bienes culturales acumulados;

e) por el carácter continuo del cambio generacional.

Estos son los fenómenos básicos que se derivan únicamente del mero hecho de la existencia de una sucesión de generaciones, de donde, por esta vez, abstraemos intencionadamente los fenómenos de envejecimiento corporal y espiritual ${ }^{28}$. En adelante, y ateniéndonos a esos puntos, intentaremos poner de relieve la importancia que esos estados de cosas elementales tienen desde el punto de vista de la sociología formal.

\section{a) La constante irrupción de nuevos portadores de cultura}

En contraste con la sociedad utópica que habíamos construido, la nuestra, que se renueva generacionalmente, está caracterizada en primer término porque la creación y la acumulación de cultura no se realiza en los mismos individuos, sino que en nuestra sociedad irrumpen constantemente «nuevos años de nacimiento».

Esto significa, para empezar, que la cultura la desarrollan hombres que tienen un «nuevo acceso» al bien cultural acumulado. A la vez, y dada la índole de nuestra estructura anímica, esa «nueva modalidad de acceso» significa un constante distanciamiento del objeto, una nueva modalidad de comienzo median-

27 Puesto que las ciencias del espíritu y las ciencias sociales no tienen a su disposición ningún experimento que sea adecuado para este caso, pudiera ser que, con frecuencia, un «experimento mental» como el que proponemos ayude a aislar los factores más importantes.

${ }^{28}$ Sobre el «ser joven», el «envejecer» y la relevancia espiritual que esos fenómenos tienen, compárense, entre otros, Spranger (se pueden encontrar en la obra de este autor más referencias sobre la vida del alma de la juventud; véase, en conexión con esto también, Honigsbeim) y, también, A. E. Brinckmann (quien trabaja con el método interpretativo de la historia del arte), Jacob Grimm, $F$. Boll (que trabajan según el método histórico-filológico). En nuestra bibliografía no hemos citado la literatura sobre la Jugendbewegung (asunto que de por sí constituye un ámbito problemático específico). Cfr. F. Boll, Die Lebensalter. Ein Beitrag zur antiken Etbnologie und zur Geschichte der Zablen, Berlín, 1913; A. E. BRInckmanN, Spätwerke grosser Meister, Frankfurt, 1925; J. Grimm, Über das Alter, Reclams Universal Bibl., n." 5311; P. Honicisheim, «Die Pubertät», Kölner Vierteljabreshefte für Soziologic, III (1924), 4; SPRANG, PR, Psychologie der Jugendalters, Leipzig. 1925. 
te la apropiación, elaboración y desarrollo de lo que está a disposición (530531). Por lo general, la «nueva modalidad de acceso» es un fenómeno relevante en la vida social, y que sólo en ella encuentra una realización específica. En la vida de los individuos tiene gran significación el hecho de que el destino les obligue a dejar su grupo de origen y a ingresar en nuevos grupos sociales: cuando un joven deja su familia, o un campesino abandona el campo, para emigrar a la ciudad; cuando un emigrante deja su patria, cuando un trepador cambia de lugar o de clase social. Como se sabe, en todos esos casos sucede con toda evidencia una alteración muy esencial en la postura de la conciencia; una mudanza no sólo en cuanto a la propia clase de contenido del material que se recibe, sino en la propia disposición anímico-espiritual. Pero todas estas formas de «nueva modalidad de acceso» se caracterizan porque ocurren siempre en el ámbito de una vida individual, mientras que, por contra, la que el fenómeno de la sucesión generacional establece se fundamenta en la irrupción de nuevas unidades vitales, corporales y anímicas que realmente empiezan una «nueva vida». Se puede decir que el joven, el campesino, el emigrante, el trepador empiezan una «nueva vida», pero sólo lo hacen en un sentido restringido; mientras que en el otro caso, en cambio, el «nuevo acceso» al bien sociocultural no lo establecen las transformaciones sociales, sino que se debe a determinaciones vitales. De acuerdo con esto, distinguimos entre dos tipos esencialmente diferentes de «nuevas modalidades de acceso» al ámbito social y al contenido de éste: el que se fundamenta en los desplazamientos sociales y el que se basa en los momentos vitales (cambio generacional). Potencialmente, el último es mucho más radical, porque la mudanza de la disposición se realiza en los nuevos portadores, y para éstos no conserva la misma relevancia lo que en la historia anterior había sido objeto de apropiación.

Si el cambio de generación no se diera, el fenómeno específico del «nuevo acceso» que se fundamenta en lo vital no tendría lugar. Al ser siempre, en este caso, los mismos hombres portadores y agentes del desarrollo del bien cultural, serían posibles, ciertamente, «nuevas modalidades de acceso» debidas a los desplazamientos sociales, pero faltarían esas formas más radicales de «nuevas modalidades de acceso» (531-532). Sería mucho más probable así que, una vez adoptadas, las intenciones básicas (las disposiciones vivenciales, las direcciones del pensamiento) se conservarían permanentemente - lo cual en sí mismo es una ventaja, pero una ventaja lastrada por una unilateralidad fija y fatal- Sólo si esos hombres utópicos gozaran de una conciencia total, igualmente utópica, si vivenciaran todo lo vivenciable, pudieran saber todo lo que puede saberse y gozaran de una elasticidad como para poder empezar siempre de nuevo, sólo entonces se compensaría, hasta cierto punto, la falta de la sucesión de generaciones. Sólo con esa «elasticidad interior», esa «nueva modalidad de acceso», establecida por los desplazamientos históricos y sociales, podría bastar para reconfigurar la vida interior y exterior de acuerdo con las nuevas circunstancias. Si partimos de la contraimagen utópica que se ha propuesto, resulta visible que, en nuestra vida social, el hecho de la irrupción constantemente renovada de hombres nuevos es la compensación directa del 
hecho de la parcialidad de cada conciencia individual. La irrupción de nuevos hombres hace, ciertamente, que se pierdan bienes constantemente acumulados; pero crea inconscientemente la novedosa elección que se hace necesaria, la revisión en el dominio de lo que está disponible; nos enseña a olvidar lo que ya no es útil, a pretender lo que todavía no se ha conquistado.

\section{b) La salida constante de los anteriores portadores de cultura}

Con lo que acabamos de decir se ha aludido ya a lo que es más esencial en el fenómeno destacado en segundo lugar, la constante salida de los anteriores portadores de cultura. El morir de las generaciones anteriores proporciona el olvido que se hace necesario en el acontecer social. Para la continuación de la vida de nuestra sociedad, el recuerdo social es exactamente tan necesario como el olvido o la irrupción de nuevos actos.

En este punto es preciso, sin embargo, replantear con qué configuración social está presente el recuerdo y cómo se realiza la acumulación cultural en la sociedad humana. Puesto que lo anímico y espiritual sólo existe en la medida en que se produce y se reproduce actualmente, las vivencias y las experiencias pasadas sólo tienen relevancia en la medida en que están disponibles en la realización actual. Las vivencias pasadas pueden, en este sentido, estar presentes de dos modos (por esta vez y en atención al propósito que preside nuestras consideraciones, trataremos sólo esas dos modalidades) (532-533):

1) Como modelos conscientes ${ }^{29}$ por los que uno se orienta, como - tan sólo por poner un ejemplo- la Revolución francesa, por la que se orientan, consciente o semiconscientemente, la mayor parte de las revoluciones posteriores; o bien

2) Inconscientemente «comprimidas», sólo «intensiva», «virtualmente» presentes: como están todas las experiencias pasadas en la configuración concreta de una herramienta; o como ocurre en una forma específica de vivencia (el sentimentalismo, por ejemplo), donde la historia de la vida del alma está virtualmente contenida. Cada realización actual opera selectivamente (en la mayoría de los casos, de manera inconsciente): lo tradicional se acomoda a las nuevas situaciones presentes; o bien se configura lo que es nuevo y, entonces,

29 Este no es el lugar adecuado para enumerar la multiplicidad completa de las formas del recuerdo social. Se fijarán aquí con intencionada restricción y simplificación las dos posibilidades polares del recuerdo social. Por «modelos conscientes» en el más amplio sentido puede entenderse todo saber global que se almacena en nuestras bibliotecas. Ese saber disponible en las bibliotecas sólo se trae constantemente a consideración para la continuación de la vida en la medida en que siempre vuelve a actualizarse. Pero éste puede actualizarse de dos modos, como forma previa o saber previo que regula intelectualmente la conducta y que le sirve a uno para orientarse, o como experiencia comprimidamente presente en la realización. Un tratamiento aparte necesitan las esferas del instinto y las copresentes esferas reprimidas y subconscientes -especialmente tratadas por Freud. 
es frecuente descubrir en lo tradicional «aspectos», posibilidades sugeridas, que inmediatamente antes no habían sido reconocidos ${ }^{30}$.

En los escalones primitivos de la vida social se produce más bien una selección inconsciente. Lo pasado está allí más bien «comprimida», «intensiva», «virtualmente» presente. Esa modalidad selectiva inconsciente también funciona en aquellos sedimentos anímico-espirituales que están más profundamente situados en el presente escalón de la existencia social, en los cuales el tempo de desarrollo no es tan relevante. Sólo es preciso que la selección se haga consciente, que se torne reflexiva, alli donde ya no bastan las transformaciones semiconscientes de los tradicionalistas. Fundamentalmente se racionalizan y se hacen reflexivas sólo aquellas esferas que se han vuelto cuestionables por las transformaciones de la contextura histórico-social, aquellas donde la transformación necesaria ya no se realiza sin reflexión y donde la reflexión viene a convertirse en una técnica de desestabilización (533-534).

En los planos culturales que antes se nos hacen visibles por medio de la reflexión sólo están contenidos aquellos elementos que —en algún momento y lugar del curso del proceso de la vida - se han vuelto problemáticos; lo cual no quiere decir que aquello que una vez se hizo reflexivo y problemático no pueda regresar a lo aproblemático, al intacto fondo de la vida. Se puede decir, y vale para todos los casos, que aquellas formas del recuerdo social que poseen reflexivamente el pasado son mucho menos relevantes (hasta su propia extensión tiende a ser comparativamente insignificante) que aquellas otras en las que dichas formas están virtual, intensivamente presentes. También cabe decir que lo que se convierte en reflexivo es mucho antes función de lo irreflexivo que al contrario.

Ahora bien, es esencial distinguir aquí entre el recuerdo que ha sido objeto de apropiación y el recuerdo que fue individualmente obtenido por uno mismo (distinción que vale tanto para contenidos reflexivos como para los no reflexivos). Hay una diferencia esencial entre haberme limitado simplemente a recibirlo y no haberlo hecho. Sólo poseo verdaderamente el recuerdo que he obtenido por mí mismo, el saber que verdaderamente he obtenido yo en situaciones reales. Sólo ese saber queda fijado. Pero, además de fijarse, ocurre que sólo ese tipo de saber sujeta de verdad. Por un lado, sería un valor deseable que todo lo que el hombre poseyese en el alma y en el espíritu fueran recuerdos adquiridos directamente por él. Sin embargo, en ese caso el peligro estribaría en que los más tempranos modos del tener y de la apropiación pudieran reprimir todas las nuevas apropiaciones que se añadan después. En muchos aspectos es ventajoso que los ancianos sean más expertos que los jóvenes. Por otra parte, su gran falta de experiencia significa para la juventud una disminución del lastre, una facilidad para proseguir la vida. Alguien es viejo, ante todo, cuan-

30 Ese redescubrimiento de las posibilidades que se desprenden de lo tradicional, que se produce al realizarse lo nuevo, nos permite comprender el hecho de que los movimientos reformadores y revolucionarios puedan enlazar a menudo sus nuevas verdades con las antiguas. 
do $^{31}$ vive en el contexto de una experiencia específica que él mismo obtuvo y que funciona como una preconfiguración, por cuyo medio cualquier nueva experiencia recibe de antemano, y hasta cierto punto, la forma y el lugar que se le asignan. Por contra, en la nueva vida las fuerzas configuradoras se constituyen por primera vez; en ella, todavía pueden ser asimiladas por sí mismas las intenciones fundamentales de esa conocida impetuosidad que es propia de las situaciones nuevas. Una especie que viviera eternamente tendría que aprender a olvidarse de sí misma, y compensar la falta de nuevas generaciones (534-535).

\section{c) Los portadores de una conexión generacional concreta sólo participan en un período del proceso histórico temporalmente delimitado}

También el tercer hecho básico — que los portadores de una determinada conexión generacional sólo participan en un período del proceso bistórico temporalmente delimitado - es, sin más, explicitable en conexión con el que hemos destacado hasta ahora. Los momentos destacados hasta ahora sólo han puesto de relieve los fenómenos que están conectados con el constante «rejuvenecimiento» de la sociedad. Hay capacidades que sólo pueden llegar a realizarse mediante la efectividad de los nuevos nacimientos, como son la de disponerse de nuevo a partir de la nueva sustancia vital, o la de formar un nuevo destino, nuevas formas de expectativas preconfiguradoras a partir de un nuevo contexto de experiencia. En oposición a esos momentos que se dan sólo con el rejuvenecimiento social, habrá que comprender más exactamente el fenómeno de la «afinidad de posición», que ya se indicó pero que no ha sido aún explícitamente analizado ${ }^{32}$.

${ }^{31} \mathrm{Si}$ se ignoran por esta vez - como se propuso anteriormente- los momentos vitales biológicos del envejecimiento corporal y anímico.

32 Debe acentuarse que ese «poder disponerse de nuevo» al que se alude en ese sentido nada tiene que ver con ser «conservador» o «progresista». No hay nada más incorrecto que suponer como presume acríticamente la mayoría de los teóricos de las generaciones- que la juventud sea en sí misma progresista y la vejez en sí misma conservadora. Las experiencias del presente bastan para señalar que la generación de más edad, la generación liberal, puede ser en lo político más progresista que determinados círculos juveniles (corporaciones estudiantiles alemanas, etc.). «Conservador»y «progresista» son categorías bistórico-sociológicas, que están orientadas por una determinada dinámica histórica de contenido concreto, mientras que «anciano», «joven», «nueva modalidad de acceso propio de la generación», son categorías pensadas desde la sociología formal. Para decidir si una juventud determinada es conservadora, reaccionaria o progresista hay que considerar (aunque tampoco exclusivamente, pero si en primer término) si ésta cuenta, desde su correspondiente lugar social, con el estatus que ha encontrado en la sociedad como una oportunidad para la propia promoción social y espiritual. Pero su «ser joven», su «nueva modalidad de acceso», se demuestran, entre otras cosas, porque, estando la juventud inmersa en el seno de esas corrientes que seleccionaremos de ahora en adelante, realiza con mayor facilidad una transformación y adaptación de las mismas a la nueva situación total; así, en la corriente conservadora, es capaz de encontrar para dicha orientación político-espiritual una forma correspondiente 
De entrada, una generación está situada de un modo afín cuando participa paralelamente en un mismo período del acontecer colectivo. Pero esto proporciona una determinación puramente mecánica y externa del fenómeno de la posición. Si antes nos hemos referido a la estructura del recuerdo, tenemos ahora que atender al fenómeno de la estratificación de la vivencia (535-536). Lo que constituye la posición común en el ámbito social no es el hecho de que el nacimiento tenga lugar cronológicamente al mismo tiempo -el hecho de ser joven, adulto o viejo en el mismo período que otros--, sino que lo que la constituye primariamente es la posibilidad, que en ese período se adquiere, de participar en los mismos sucesos, en los mismos contenidos vitales; más aún, la posibilidad de hacerlo a partir de la misma modalidad de estratificación de la conciencia. Resulta fácil probar que el hecho de la contemporaneidad cronológica no basta para constituir posiciones generacionales afines. Nadie querría sostener que la juventud china y la alemana se encontraran en afinidad de posición en torno a 1800 . Sólo se puede hablar, por lo tanto, de la afinidad de posición de una generación inserta en un mismo período de tiempo cuando, y en la medida en que, se trata de una potencial participación en sucesos y vivencias comunes y vinculados. Sólo un ámbito de vida histórico-social común posibilita que la posición en el tiempo cronológico por causa de nacimieno se haga sociológicamente relevante. Traigamos aquí de nuevo a consideración el mencionado fenómeno de la estratificación de la vivencia. Incluso las más viejas generaciones que todavía están presentes vivencian recorridos parciales del acontecer histórico junto a la juventud adolescente y, no obstante, no se les puede atribuir la misma posición. El hecho de que desentonen es esencialmente comprensible gracias al fenómeno de la diversificada estratificación de la vida. El carácter estructural de la conciencia humana se puede caracterizar por medio de una determinada «dialéctica» interna. Para la formación de la conciencia es en gran medida decisivo cuáles sean las vivencias que se depositan como «primeras impresiones», como «vivencias de juventud», y cuáles sean las que vienen en un segundo o tercer estrato, y así sucesivamente. Más aún: resulta ser completamente decisivo para una «experiencia» que ha de ser vivenciada por un individuo -así como también para la formación y la relevancia de ésta- el hecho de que opere como una decisiva primera impresión de juventud, o que no lo haga y funcione, por tanto, como una «vivencia tardía». Las primeras impresiones tienden a quedar fijadas como una imagen natural del mundo. Por consiguiente, cualquier experiencia tardía se orienta por medio de ese grupo de vivencias, y puede ser que sea sentida como confirmación y satisfacción de ese

con la situación moderna; en el socialismo, una forma de esa tradición adaptada al presente. Esto también constituye una valiosa prueba de la tesis principal de esta contribución, que después será aún más detalladamente confirmada, a saber: que los hechos vitales (como el ser joven o el envejecer) no implican inmediatamente, en cuanto al contenido, determinados modos de comportamiento espiritual (como equiparar incondicionalmente ser joven con ser progresista, etc.), sino que implican únicamente tendencias formales que sólo pueden convertirse en relevantes en los elementos sociales y espirituales. Toda equiparación o combinación directa de los datos biológicos con las manifestaciones espirituales conduce a un quid pro quo, que sólo suscita confusión. 
primer estrato de experiencia o, por el contrario, como su negación o antítesis (536-537). Incluso las vivencias reunidas en el curso de la vida no se acumulan sencillamente por adición y amontonamiento, sino que se articulan «dialécticamente» en el sentido ya descrito. No podemos aquí perseguir en detalle esa específica articulación dialéctica que está potencialmente presente en cualquier obrar, pensar y sentir que se realiza actualmente (lo «antitético» sólo es una forma de agregación de las vivencias tardías a las anteriores). Pero todo esto es seguro; el predominio de las primeras impresiones permanece vivo y determinante, aun cuando todo el decurso sucesivo de la vida no tenga que ser otro que una negación y una descomposición de la «imagen natural del mundo» recibida en la juventud. Pues también en la negación se orienta uno por lo negado y se deja involuntariamente determinar por ello. Si se considera ahora que cualquier vivencia concreta recibe su semblante, su determinada configuración, a través de ese orientarse por las vivencias primordiales, se hace entonces comprensible la significación que ese primer estrato de la conciencia tiene para la ulterior configuración de los contenidos de la conciencia. Una de las ulteriores manifestaciones -emparentada con el fenómeno que acabamos de analizar- es el hecho de que dos generaciones que se siguen entre sí combaten siempre, en el mundo y en sí mismas, cada una a un antagonista distinto. Mientras que los viejos combatían algo que todavía había en ellos o en el mundo externo, y orientaban hacia ese antagonista todas las intenciones de su sentimiento y de su voluntad y también las aclaraciones conceptuales, para la juventud, en cambio, ese antagonista ha desaparecido. Para esa generación la orientación primaria se establece en otra parte completamente distinta. En gran medida es de ese desplazamiento de la «vivencia polar»-que se produce al desaparecer el contrincante interior y exterior, cuyo puesto es continuamente ocupado por otro- de donde nace, en el proceso histórico, aquel desarrollo no rectilíneo que tan frecuentemente se ha observado, especialmente en la esfera de la cultura. Esa «dialéctica» que comienza con el cambio generacional faltaría en esa sociedad nuestra que habiamos construido utópicamente. En ella, sólo las polaridades sociales -en la medida en que estuvieran presentes- podrían ejercer como momentos dialécticamente efectivos (337-338). Los hombres de esa sociedad utópica tendrían como primer estrato de experiencia las primeras experiencias históricas de la humanidad, y todo lo que viniera después estaría fundamentalmente orientado por ellas.

\section{d) La necesidad de la tradición - transmisión - constante de los bienes culturales acumulados}

La necesidad de una tradición - transmisión - constante de los bienes culturales acumulados condiciona también determinadas estructuras a las que al menos tenemos que aludir aquí. En este caso sólo van a ser momentáneamente citadas. Una utópica generación que se diera solitariamente y de una vez para 
siempre podría desconocer la necesidad de la tradición. Lo más esencial en toda tradición es hacer que las nuevas generaciones crezcan en el seno de los comportamientos vitales, de los contenidos sentimentales y de las disposiciones que han heredado. Frente a eso, lo que se enseña de forma consciente es de alcance más limitado, tanto cuantitativamente como desde el punto de vista de la significación. Todos aquellos contenidos y disposiciones que siguen funcionando sin problemas en la nueva situación vital $-\mathrm{y}$ que constituyen así el «fondo vital» ${ }^{33}$ - se transmitirán inconscientemente; serán legados, transmitidos, involuntariamente, sin que ni maestro ni pupilo sepan nada al respecto. Lo que se enseña o se inculca de manera consciente pertenece a ese sedimento que, en algún lugar y en algún momento del curso de la historia, se ha vuelto problemático y reflexivo. Por eso también ocurre a menudo que ese fondo (que simplemente se infiltra por «influencia del milieu» durante el primer tiempo de juventud) sea el estrato histórico más antiguo de la conciencia, y que, en cuanto tal, tienda a establecerse y estabilizarse como imagen natural del mundo 34 (538-539).

También en la primera juventud se recogen contenidos reflexivos tan ampliamente «aproblemáticos» como esos sedimentos vitales más profundamente depositados. El nuevo germen de vida anímico-espiritual, que está presente de forma latente en los nuevos hombres, todavía no llega en absoluto a ser él mismo en sentido propio. La posibilidad de la «puesta en cuestión» nace a los 17 años $^{35}$ - a menudo antes, frecuentemente después-, en el momento en que comienza la vida autoexperimentada. Sólo entonces, la vida

${ }^{3}$ Nota del traductor: En este pasaje, Mannheim recurre en varias ocasiones a la expresión francesa fonds (capital, fondos) y la utiliza sola o (como en este caso y como puede verse también en la nota siguiente) para construir palabras compuestas con sustantivos alemanes, como Leben (vida) o Seele (alma).

${ }^{3+}$ Es difícil determinar el momento en que se cierra en el individuo ese proceso; difícil es establecer el momento a partir del cual apenas prosigue la constitución de ese fondo vital inconsciente (en el que descansan también las propiedades nacionales y regionales; del que arrancan las «entelequias» regionales y nacionales). El proceso parece estar cerrado cuando ese fondo vital aproblemático apenas se altera ya directamente. El chico, el joven que es arrojado a un nuevo milieu, siempre está en situación de estar abierto a nuevas influencias de ese tipo. Dejan éstos, sin más, que se infiltren en ellos nuevas posturas animicas, nuevas costumbres; que su lenguaje y dialecto cambien. El adulto, transferido a una nueva situación vital, sólo transforma conscientemente ciertos aspectos de sus modos de comportarse y de pensar, pero nunca lo hace de esa manera radical. En la mayoría de los casos, las posturas más fundamentales de ese fondo del alma - -y, en lo externo, también el habla y el dialecto- permanecen en escalones anteriores. Parece, por tanto, que se puede encontrar un indicio indirecto del cierre de ese proceso en el habla y en la pronunciación. Si se puede comprobar cuándo se cierra el proceso de adquisición del habla, del dialecto del individuo, dispondríamos al menos de un punto de apoyo para fijar el momento en el que se haya de situar el cierre de la constitución del fondo vital en el individuo. Según las investigaciones científicas del lenguaje propuestas por $A$. Meillet, el lenguaje cotidiano, el dialecto del individuo, apenas cambia a partir de los 25 años (A. MEILlet, Metbode dans les sciences, París, Alcan, 1911; véase del mismo autor, además, Introduction a l'étude comparative dés langues indo-europécnnes, 1903 , citado por MENTRE, op. cit., pp. $306 \mathrm{ss}$.).

${ }_{35}$ También Spranger establece un importante corte en torno a los 17 años. 
crece por vez primera desde la problemática «presente» y tiene la oportunidad de experimentar esa problemática en sí misma. Sólo entonces se constituirán aquellos estratos de los contenidos de la conciencia y aquellas disposiciones que - debido a la nueva posición histórica y social- han pasado a ser problemáticos y que, por eso, se han hecho conscientes; sólo entonces se está verdaderamente «presente». La lucha de la juventud combatiente se produce en torno a esos sedimentos, y si sigue siendo radical, no se percata de que en realidad sólo transforma el sedimento superior de la conciencia que se ha hecho reflexivo. Parece ser, pues, que los sedimentos más profundos no se desestabilizan ${ }^{36} \sin$ más y, también, que cuando se hace necesario los procesos se insertan en el plano reflexivo y que es a partir de ese plano como lo habitual se transforma ${ }^{37}$. El hecho de que la juventud «esté presente» significa, por lo tanto, que está más cerca de la problemática (a consecuencia del «nuevo acceso potencial», etc.) (539-540); significa, incluso, vivenciar como antítesis primaria lo que se ha concebido en una situación de desestabilización y, también, vincularse en la lucha contra ésta. Mientras tanto, la vieja generación persiste en su más temprana reorientación.

Partiendo de ahí, se ve hasta qué punto es difícil conseguir una educación y una enseñanza adecuadas (en el sentido de la completa transmisión de los ejes de la vivencia que son necesarios para el saber activo), puesto que la problemática vivencial de la juventud se plantea frente a un contrincante distinto al del maestro. Dejando al margen el caso de las ciencias exactas, hay que decir que no se trata en esos casos de la relación de un representante de la conciencia en general con otro, sino de la relación entre un posible eje de

${ }^{36}$ Desde este punto de partida puede hacerse comprensible la «anticipación» de las transformaciones reales por medio de las ideas. Hay que pensar aquí en el concepto francés de idée y no en el «original» de la «idea platónica». Esa «idea moderna» tiende a desestabilizar y a poner en movimiento el contexto social. No está presente en las unidades sociales estáticas - como son los ambientes vitales campesinos que todavía se mantienen cerrados sobre sí mismos- por cuanto en ellas uno se alimenta aún aproblemáticamente de ese fondo que se ha transmitido de manera inconsciente. Por lo demás, tampoco ocurre en ese caso que la nueva generación se contradistinga de los mayores precisamente mediante una adhesión ideológica de ese tipo. El «ser joven» sólo se produce aquí en la diferenciación biológica. Después trataremos más sobre esta cuestión.

${ }^{37}$ El orden en el que vienen a hacerse valer los factores productivos parece ser el siguiente. Primeramente varían las «circunstancias». Las realizaciones actuales, que de esa manera se plantean en una situación nueva, se transforman inicialmente de manera inconsciente. Se procura hallar una vía de acceso a la nueva situación por medio de una adaptación que se produce instintiva, inconscientemente. (Incluso el hombre ortodoxo, fiel a los principios, se adapta continuamente a las cosas que no caen en el ámbito de la observación consciente.) En el caso de que la transformación sea demasiado violenta debido a la acelerada dinámica del proceso social y espiritual, la adaptación inconsciente ya no bastaría. Las realizaciones no «funcionarían» en una situación que se ha hecho nueva demasiado repentinamente (es decir: algo se habrá vuelto realmente problemático en ella). Es en ese caso cuando la conciencia reacciona con una concienciación - cuya figura concreta se corresponderá con el respectivo nivel de conciencia histórica (mito, filosofía, ciencia) - y provoca en adelante, en la medida de lo posible, el relajamiento de los más profundos sedimentos del alma. 
orientación de la vida y el subsiguiente. Esta tensión ${ }^{38}$ sería casi insuperable mediante la tradición de la experiencia vital si, de hecho, no se diera la tendencia retroactiva: pues no sólo educa el maestro al discípulo, sino que el discípulo educa también al maestro. Las generaciones están en incesante interacción.

\section{e) El carácter continuo del cambio generacional}

Venimos así a tratar el punto siguiente: el fenómeno del carácter continuo del cambio generacional, gracias al cual esa retroacción de la que hablábamos ocurre sin fricciones. Para empezar, en el curso de ese equilibrio retroactivo no se enfrentan la generación más vieja y la más joven, sino las «generaciones intermedias», que están más próximas entre sí. Son éstas las que se influyen recíprocamente ${ }^{39}$.

Por suerte, frente a la opinión de la mayoría de los teóricos de las generaciones, la distancia de treinta años no es decisiva; todos los niveles intermedios se conjugan, todos influyen, y aunque no lleguen a neutralizarla, al menos equilibran la diferenciación biológica de las generaciones de la sociedad. Ese reflejo de la problemática de las generaciones jóvenes sobre las más viejas se hace tanto más dominante cuanto más se acrecienta el dinamismo de la sociedad (540-541). Las circunstancias estáticas producen el valor sentimental de la piedad; la juventud tiene entonces la tendencia a acomodarse a los mayores, incluso a parecer externamente mayor. Un dinamismo acrecentado, al elevarse a la conciencia, hace que las generaciones mayores estén abiertas a la juven$\operatorname{tud}^{40}$. Ese proceso puede crecer hasta el punto de que la generación mayor sea en determinadas esferas (merced a una elasticidad que ha obtenido de la experiencia de la vida) más capaz de adaptación que las generaciones intermedias, que aún no están dispuestas a desistir de su primera disposición vital ${ }^{41}$. De modo que el continuo cambio de las circunstancias se corresponde con el carácter continuo de la juventud que se orienta preferentemente por esas

${ }^{38}$ L. von Wiese retrata esa oposición padre-hijo de un modo muy gráfico. Sumamente valiosa es su advertencia de que el padre se ve instado por la tendencia a representar a la «sociedad» frente a su hijo. Cfr. L. VON WIESE, Allgemeine Soziologie als Lebre von den Beziebungsgebilden, München und Leipzig, 1924, pp. 196 ss.

${ }^{39}$ Propondremos también en este caso un ejemplo actual. Un artículo de fondo de la Frankfurter Zeitung ( 8 de diciembre de 1927) a propósito del conflicto sobre los derechos estudiantiles prueba con bastante exactitud el cambio en el modo de orientar la vida que se ha producido - y que ya es hoy visible- entre la generación posterior a la guerra y la generación intermedia que sigue a ésta: también se encuentra ahí un justificante para el equilibramiento que se produce entre ambas.

to Hay que notar una tendencia contraria con respecto a ésta en el hecho - sobre el cual $L$. von Wiese ha reclamado atención- de que, a partir del individualismo moderno, cada cual reclama en mayor medida que antes el derecho a vivir su propia vida. Cfr. L. VON WIEsE, Allgemeine Soziologie als Lebre von den Beziebungsgebilden, op. cit, p. 197.

${ }^{41}$ Eso también prueba que las fuerzas sociales paralizan los factores biológicos naturales que, en definitiva, caracterizan la edad; que en el elemento social los datos biológicos se pueden tornar casi en lo contrario de lo que son. 
transformaciones. La nueva juventud que irrumpe vivenciará, como nuevos y relevantes, cambios de situación cada vez más pequeños, y los miembros de generaciones intermedias se introducen entre la reorientación más antigua y la nueva. El fondo vital - que subyace intacto- es en sí mismo vinculante; la constante interacción entre el joven y el viejo amortigua las diferencias, y la continuidad de las transiciones hace que en los tiempos tranquilos la transformación se produzca sin fricciones. Resumiendo: si en el proceso social no se diera ninguna generación nueva, si no fuese posible la reverberación -que sólo lo es a partir de los nuevos gérmenes de vida-, ni los nuevos comienzos fuesen susceptibles de experiencia, y tampoco se diera continuidad alguna en la sucesión de generaciones, ese equilibrio no podría realizarse nunca sin fricciones.

\section{LA POSICIÓN GENERACIONAL, LA CONEXIÓN GENERACIONAL, LA UNIDAD GENERACIONAL}

Esos son, en resumen, los momentos que se pueden distinguir sobre la base de un análisis abstracto del fenómeno generacional considerado en sí mismo (541-542). Dichos momentos pueden determinar la efectividad de la generación, siempre que se la valore como un puro dato natural y siempre que el fenómeno de la generación esté perfectamente descrito al tomarlo como un mero fenómeno de posición. Pero la «posición generacional» (Generationslagerung) no puede equipararse con la «conexión generacional» (Generationszusammenbang) ${ }^{42}$. La conexión generacional es más determinante que la mera posición generacional, de la misma forma que la mera situación de clase no puede equipararse a una clase que se autoconstituye. La posición sólo contiene posibilidades potenciales que pueden hacerse valer, ser reprimidas, o bien modificarse en su realización al resultar incluidas en otras fuerzas socialmente efectivas. Nos hemos acercado ya lo suficiente al fenómeno sobre el que vamos a tratar a partir de ahora, como para que tengamos que reconocer que la mera contemporaneidad biológica no basta para constituir una posición generacional afín. Para estar incluido en una posición generacional, para soportar pasivamente los frenos y las oportunidades de esa posición, pero también para poder utilizarlos activamente, tiene uno que haber nacido en el mismo ámbito histórico-social —en la misma comunidad de vida histórica- y dentro del mismo período. Sin embargo, la conexión generacional es algo más que esa mera presencia circunscrita en una determinada unidad histórico-social. Para que se pueda hablar de una conexión generacional tiene que darse alguna otra vinculación concreta. Para abreviar, podría especificarse esa adhesión como una participación en el destino común de esa unidad histórico-social ${ }^{43}$. Nuestra próxima tarea ha de ser procurar una descripción más aproximada de este fenómeno.

12 Hemos usado hasta aquí indiferenciadamente generación, conexión generacional, etcétera; debemos ahora empezar a diferenciar con exactitud los significados.

43 Cfr. la cita de Heidegger en esta misma investigación. 
Hemos propuesto el ejemplo de que, en torno a 1800 , la juventud prusiana no estaba en ninguna posición generacional común con la juventud china del mismo período cronológico. En consecuencia, la pertenencia a la misma comunidad de vida histórica sirvió como primer criterio de delimitación de la posición generacional. ¿Pero dónde está la frontera inferior? ¿Acaso hay que contar a los campesinos - que vivían en una región completamente alejada y que, por entonces, apenas, o sólo muy escasamente, estaban afectados por las perturbaciones globales - en la misma conexión generacional en la que, en esa misma época, hay que incluir a la juventud de las ciudades? (542-543). Seguro que no, y tanto más por cuanto aquéllos no llegaron a ser directamente captados por las revoluciones sociales y espirituales que impulsaba la juventud ciudadana. Sólo hablaremos, por lo tanto, de una conexión generacional cuando los contenidos sociales reales y los contenidos espirituales establecen - precisamente en los terrenos de lo que se ha desestabilizado y de lo que está en renovación - un vínculo real entre los individuos que se encuentran en la misma posición generacional. Entonces, la mencionada juventud campesina sólo se encuentra en la correspondiente posición generacional, pero no participa de la conexión generacional en cuestión. Se encuentra en la misma posición generacional en la medida en que puede incluirse potencialmente en los nuevos destinos. Lo que también sucedió en las guerras de liberación fue que su élan conmovió de algún modo a toda la nación. En casos así, la mera posición generacional de los hijos de los campesinos se convierte en una participación en la conexión generacional. Los individuos coetáneos estaban -y en general siempre están- vinculados por medio de una conexión generacional, sólo en la medida en que participaban en aquellas corrientes sociales y espirituales que constituían precisamente el momento histórico respectivo, y en la medida en que tomaban parte, activa y pasivamente, en aquellas interacciones que conforman la nueva situación —al darse por aquel entonces un toma y daca de ese tipo prácticamente entre todos los estratos, se produjo el entusiasmo-. Si queremos seguir esa pista a partir de aquí, se nos plantea entonces una cuestión. Si pasamos por alto desde ahora todos aquellos estratos sociales que no participan en lo que está en renovación, entonces, siempre se puede cuestionar si hay que incluir en la misma generación a todos los grupos que participan en lo que está en renovación. Por ejemplo, a partir de 1800 - dicho sea esto de paso- un grupo romántico, que con el correr del tiempo se hacía más y más conservador, se oponía de forma cada vez más ostensible a una juventud que se iba haciendo racionalista-liberal. No se puede seguir manteniendo que esos grupos están vinculados por los mismos contenidos modernos. ¿Debemos hablar en esos casos de una conexión generacional unitaria? Creemos que podemos hacerlo, sin más, si acometemos una fijación de términos más exacta (543-544). Tanto la juventud románticoconservadora como la liberal-racionalista pertenecen a la misma conexión generacional; pues el conservadurismo romántico y el racionalismo liberal eran a la sazón únicamente las dos formas polares de un enfrentamiento social 
y espiritual plenamente relativo, en cualquier caso, a un mismo destino histórico real. Toda la juventud contemporánea - que es romántico-conservadora y liberal-racionalista - vive en una misma conexión generacional, pero está siempre vinculada por dos unidades generacionales distintas. La unidad generacional es, por tanto, una adhesión mucho más concreta que la que establece la mera conexión generacional. La propia juventud que se orienta por la misma problemática bistórica-actual, vive en una «conexión generacional»; dentro de cada conexión generacional, aquellos grupos que siempre emplean esas vivencias de modos diversos constituyen, en cada caso, distintas uunidades generacionales» en el ámbito de una misma conexión generacional.

\section{LOS FACTORES QUE ESTABLECEN LA UNIDAD EN EL ÁMBITO DE LOS FENÓMENOS GENERACIONALES}

La cuestión es ahora ésta: ¿qué es lo que produce una unidad generacional?, ¿en dónde se apoya esa mayor intensidad de adhesión que se manifiesta en este caso? Cuando uno fija la vista en una determinada unidad generacional, lo primero que asombra es el gran parecido que hay entre los contenidos que ocupan la conciencia de los individuos. Desde una perspectiva sociológica, los contenidos de la conciencia tienen significatividad, no sólo por lo que de sustancial hay contenido y abarcado en ellos, sino también por el hecho de que son los que vinculan a los individuos con el grupo, porque tienen efecto «socializador». Por ejemplo, la idea de libertad era importante para la unidad generacional liberal, no sólo por el contenido de las demandas que entrañaba, sino porque en esos contenidos y a través de ellos los individuos diseminados espacialmente o de cualquier otro modo podrían vincularse en una unidad ${ }^{44}$ (544-545). Pero no son los contenidos lo que vincula prioritariamente a los individuos; vinculan todavía más aquellas fuerzas formativas que los configuran; pues, en realidad, los contenidos reciben primero un cuño y una determinada dirección. Una misma tendencia formativa opera a menudo con una amplia variedad de formas - desde una consigna acuñada hasta el sistema ya construido, desde un gesto aparentemente aislado hasta la obra de arte que ya ha sido formada-; una misma tendencia formativa cuyo significado social consiste, precisamente, en que, por ella y en ella, se hace posible la vinculación social de los individuos. El profundo significado «emocional» de una consigna, de un gesto auténtico o de una obra de arte, consiste en que, con ellos, no sólo se acogen los contenidos,

4t Los contenidos pueden vincular y diferenciar socialmente. Por ejemplo, el mismo concepto de libertad tenía en la «unidad generacional» de los liberales una significación completamente distinta a la que tenia en la de los conservadores. De modo que los análisis de los significados pueden emplearse como medida segura para la diferenciación de la conexión generacional en unidades generacionales. Cfr. Karl ManNHEM, «Das Konservative Denken», Archiv für Sozial Wissenscbaft und Sozialpolitik (1927), 57, 1, pp. 68-142; 57, 2, pp. 470-495, donde el concepto conservador de libertad, tomado en su significado específico, se trata en contraposición con el concepto contemporáneo que al respecto tenían los liberales. 
sino también las tendencias formativas y las intenciones vinculantes básicas que éstos llevan incorporadas, y en que, por medio de ellos, se vincula uno con las voluntades colectivas.

Las intenciones básicas y los principios configuradores son lo fundamental -incluso para cada tradición particular-; lo son porque sólo ellos socializan verdaderamente y porque sólo ellos pueden de verdad tener continuidad - lo cual tal vez sea aún más importante-. Una mera constatación sólo socializa mínimamente y sólo contiene en una medida muy modesta el germen de la posibilidad de continuar. La posibilidad de que el pensamiento continúe reside en una tesis que socializa de verdad; la nueva dirección - aquella en la que se podrán continuar la visión, el sentimiento y la obra de arte, y en la que éstos podrán ser revitalizados y existencialmente reinterpretados ante las nuevas situaciones vitales - reside en una visión, en un sentimiento y en una obra de arte socialmente vinculados. Por eso, la univocidad (una certeza excesivamente acusada) tampoco es un valor social insignificante; una incomprensión productiva es a menudo la fórmula de supervivencia. Las intenciones básicas y los principios configuradores son los factores de socialización que actúan en primera línea en el acontecer sociohistórico. Es preciso crecer desde ellos, si de verdad se quiere participar en el acontecer colectivo.

La psicología moderna reconoce con creciente certeza que incluso la propia percepción humana se orienta «con arreglo a configuraciones»; que nosotros no experimentamos mediante la más simple de las percepciones de cosas, como aceptaba la psicología atomística - que construía a partir de los elementos, y quería llegar a la totalidad con una suma paulatina de las impresiones particulares (los datos sensoriales) - (545-546). Se afirma, por el contrario, que lo primero que obtenemos es una impresión configuradora global. Si ese primado de la «totalidad», de la «configuración», se da ya en la percepción de cosas, tanto más se produce dicha primacía en el caso del registro de los contenidos espirituales. La necesidad humana de una orientación configurada puede tener múltiples causas. Entre ellas se puede sugerir la siguiente. A causa de su relativa angostura, la conciencia humana no es capaz de procesar la infinidad de elementos afluentes y, por eso, está constantemente obligada a recurrir a un procedimiento configurante, simplificador y sintético. Pero el hecho de ver configuradamente también tiene orígenes sociales, que hay que destacar necesaria y precisamente en ese punto. Si es cierto que la percepción de una cosa y su lógica expresión lingüística, al igual que cualquier otro contenido, no existen nunca únicamente para el individuo particular y aislado que los posee intencionalmente, sino existen también para los grupos sociales que están detrás de él, así también la captación configurada —en parte simplificadora, pero también en parte complementaria- transcurre siempre en aquella dirección, en aquella disposición en la que está el propio «objeto» del grupo social en cuestión. Las cosas ya las vemos con una determinada configuración; pensamos los conceptos con una significación determinada. En cada caso, la certeza se da a través del grupo que siempre hay detrás de 
nosotros. Crecer en un grupo no significa tan sólo realizar las valoraciones que caracterizan a ese grupo, sino también captar aquellos aspectos de las cosas, aquellos matices de la significación de los conceptos, aquella configuración de los contenidos anímico-espirituales con los que unos y otros están presentes para el grupo. Estar vinculado con un grupo significa, además, incluir en uno mismo aquellas intenciones de formación y de configuración a partir de las cuales las nuevas impresiones y acontecimientos emergentes pueden ser procesados con una dirección ampliamente prescrita.

La significación social de la existencia de esas intenciones formativas consiste en que, a través de ellas, pueden ser vinculados incluso los individuos que están espacialmente separados y que nunca han mantenido unos con otros contacto personal (546-547). Mientras que la afinidad por posición generacional sólo es algo de carácter potencial, una conexión generacional se constituye por medio de la participación, de los individuos que pertenecen a la misma posición generacional, en el destino común y en los contenidos conexivos que de algún modo forman parte de éste. Las unidades generacionales específicas pueden nacer, entonces, dentro de esa comunidad de destino. Estas unidades generacionales se caracterizan no sólo por significar diversas conexiones del acontecer vinculadas entre sí en el seno de una débil participación en común vivenciada por distintos individuos, sino también porque significan un modo de reaccionar unitario - un «agitarse juntos» y un modo de configurar que están conformados por un sentido semejante- de los individuos que están (en la medida en que lo están) directamente vinculados a una determinada conexión generacional.

En el ámbito de la misma conexión generacional pueden formarse varias unidades generacionales que luchen entre sí desde posiciones polarmente opuestas. Pues bien, esas unidades constituirán una «conexión» precisamente cuando estén en sintonía entre sí, aunque se combatan. En torno a 1810, la juventud que participaba en la conexión generacional social y espiritual pertenecía a una misma conexión generacional, sin que importe si en aquella etapa concreta participaba en las ideas liberales o en el conservadurismo coetáneo. Pero, dentro de esa conexión generacional, cada cual pertenecía a una unidad generacional distinta, según participara en las intenciones básicas de los conservadores o de los liberales.

Precisamente es gracias a esa certeza de dirección que le es inherente como la unidad generacional vincula de una forma mucho más concreta a los individuos particulares que ha captado. De hecho, en la mayoría de los casos esas nuevas intenciones generacionales básicas —que están marcadas por una impronta y que toman también una postura partidista- no surgen originariamente en libre fluctuación (nicbt freiscbweben ${ }^{45}$ ), sin que exista el contacto

4 Nota del traductor: La expresión «sozial freischwebende» es muy frecuente en algunos de los textos más conocidos de Mannheim (lo más habitual es que hable de «sozial freischwebende Intelligentsia» -o Intelligentz-). Los distintos traductores y comentaristas han acuñado, al efecto, modismos que nos parecen un tanto forzados o demasiado literales, y que proceden principalmente del calco directo de la versión 
personal. Surgen más bien dentro de grupos concretos, donde los individuos se encuentran en proximidad vital; en grupos donde éstos crecen en oposición anímica y espiritual, y en cuya comunidad de vida los propios individuos exhiben, desde ellos mismos, las intenciones básicas (que corresponden a la nueva posición) (547-548). Tales intenciones básicas y tendencias formativas -que surgieron en un momento dado en concreta vinculación con hombres aislados- pueden incluso desprenderse más tarde de esos grupos concretos, y tienen una fuerza de propaganda y de vinculación que opera a distancia.

La unidad generacional, entendida en el sentido que hemos descrito, no existe como un grupo concreto, aunque su embrión se forma también por medio de un grupo concreto; merced a un grupo que, por sí mismo, pone en el mundo las inspiraciones esenciales, los embriones susceptibles de desarrollo. Así, por ejemplo, el círculo de ideas que tan esencialmente determinante fue para el conservadurismo alemán moderno, nació originariamente en la asociación concreta de la "Christlich deutschen Tischgesellschaft». Dicha asociación había recogido y reformado por vez primera todas las corrientes irracionales correspondientes a la situación de aquel entonces y a la específica posición generacional de los jóvenes conservadores. Desde ese grupo se irradiaron originariamente las ideas capaces de propagarse a otros círculos.

Junto a ese hecho - que las intenciones básicas que crecen en un grupo concreto posean una facultad de propagarse y de vincular fuera de esos grupos concretos- encontramos el asunto principal: que esas intenciones son expresión más o menos adecuada de la posición generacional respectiva, y que hay individuos que, aunque vivan fuera de esos grupos concretos, se encuentran en afinidad de posición, y también hallan en esas intenciones básicas la expresión correspondiente a su posición en los espacios históricos. La ideología de clase se forma originariamente a partir de grupos concretos que están más estrechamente vinculados, y sólo se implanta en la medida en que exprese y configure más o menos adecuadamente las circunstancias típicas que pertenecen a una determinada posición social. Exactamente lo mismo ocurre con las intenciones básicas $\mathrm{y}$ las tendencias formativas que constituyen una unidad generacional ( $\mathrm{y}$ que son puestas en juego en el mundo por uno de esos grupos cerrados). Ocurre que dichas intenciones y tendencias sólo son verdaderamente operativas y susceptibles de expansión cuando son capaces de configurar las circunstancias típicas de los individuos que se encuentran en la misma posición generacional. Esa capacidad se prueba precisamente cuando logra dar expresión, en esos grupos cerrados, a la nueva modalidad de acceso y a la nueva modalidad de

inglesa de las obras de Mannheim («intelligentsia libre de ataduras sociales», «intelligentsia flotante», «intelligentsia que flota en libertad», etc.). Esas expresiones resultan insatisfactorias, sobre todo, por lo que tienen de lugares comunes petrificados que no invitan a mayores aclaraciones. Por eso, hemos creido oportuna la puesta en juego en este contexto de un sintagma procedente del lenguaje de la Economía como «libre fluctuación», cuya irrupción puede aportar un golpe de luz sobre el sentido propio de la noción de Mannheim, merced a la riqueza semántica que acumula al ser usualmente empleado para designar ese modo de fluctuar entre márgenes del que se habla al tratar las cuestiones cambiarias. 
«estratificación de la vivencia» de las que hemos hablado (548-549). Pero en la medida en que eso ocurre, existe cierto paralelismo entre los fenómenos de clase y los fenómenos generacionales. Veamos en qué consiste dicho paralelismo: así como una ideología es capaz de ganar terreno también al margen de sus adecuados portadores - fuera de la correspondiente situación de clase ${ }^{\text {th }}$ en épocas favorables a la ideología en cuestión, asimismo, en una circunstancia temporal idónea, suele suceder que determinados impulsos generacionales sean capaces de captar miembros individuales que nacieron en años anteriores o posteriores a la generación en cuestión.

Pero todavía podemos ir más allá. Es verdad que con mucha frecuencia ocurre que sean ciertos individuos que aún pertenecen a la generación anterior, y que se encuentran aislados dentro de ella (los precursores ${ }^{47}$ ), quienes desarrollen en ellos mismos el embrión esencial de las nuevas posturas generacionales y quienes profundicen en él a lo largo de su vida ${ }^{48}$; pero también es posible que los precursores de una ideología de clase pertenezcan todavía ampliamente a una clase extraña.

Todos esos fenómenos no indican nada contra la validez de la tesis que afirma que la existencia de ciertos impulsos básicos nuevos, que son los que vendrían a producir originariamente las unidades generacionales, se puede atribuir a una determinada posición generacional. Porque lo decisivo en todos esos casos es que el portador esencial de esos nuevos impulsos sea un portador colectivo. El asiento real de una ideología de clase sigue siendo la propia clase - esas oportunidades y obstáculos típicos que constantemente se hacen efectivos en la vida cotidiana-, aun cuando ocasionalmente su ideología la creen individuos extraños a esa clase, o cuando en el curso de su expansión dicha clase se extienda - también de forma incidental- más allá de la respectiva situación de clase (449-550). La posición generacional sigue siendo el asiento

to Así, en los años cuarenta, cuando las ideas opositoras volaban más alto, también las compartían los jóvenes de la nobleza. Cfr. K. MARX, Revolution und Kontre-Revolution

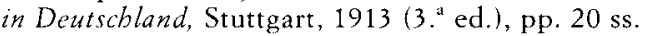

47 En su historia de la literatura, Kummer elaboró una tipología plenamente diferenciada de los representantes de una generación; distinguía constantemente entre precursores, exploradores, genios, talentos independientes que no tienen arrastre, talentos dependientes, recadistas y talentos de moda. Cfr. F. Kummer, Deutsche Literaturgeschicbte des 19. Jabrhunderts. Dargestellt nach Generationen, Dresden, 1900, pp. 6 ss. y passim.

${ }^{48}$ Nietzsche, por ejemplo, puede ser considerado como precursor de los neo-románticos actuales. En Francia es un ejemplo eminente Taine, quien, impresionado por los acontecimientos de 1870-71, experimentó el cambio hacia el patriotismo y, a partir de ese cambio, llegó a ser el precursor de una generación nacionalista (cfr. R. Platz, Geistige Kämpfe in modernen Frankreicht, Kempten, 1922, pp. 43 ss.). En esos casos que se refieren a precursores habría que comprobar, mediante una investigación históricosociológica, que la estructura vivencial de aquellos que experimentan en su propia vida una profunda transición hacia lo nuevo está, no obstante, modelada de un modo completamente distinto que la de la nueva generación, cuya vivencia empieza donde termina la de sus precursores. Un caso interesante sobre el particular es el del jurista Hugo, a quien podemos considerar como el fundador de la «Escuela histórica». Sin embargo, éste nunca consumó el cambio irracionalista que obraría después la nueva generación (Savigny), aquella que durante su juventud presenció la Guerra de Liberación. 
real del nuevo impulso (que sugiere una nueva y determinada modalidad de vivencia, y descarta otras selectivamente), aun cuando ocasionalmente pueda este impulso extenderse a años de nacimiento ajenos.

Pero aún contemplaremos lo más esencial a continuación. Lo que ocurre no es que cada una de las posiciones generacionales y cada año de nacimiento creen, desde ellos mismos y a su medida, nuevos impulsos y nuevas tendencias formativas. Cuando sucede algo de ese estilo tendríamos que hablar, más bien, de la activación de una potencialidad de la posición que estaba dormida. Parece probable que la intensidad de la activación esté conectada con la velocidad de la dinámica social ${ }^{49}$. Si las revoluciones socioespirituales introducen un tempo que acelere la transformación de las disposiciones hasta el punto de que no sea ya posible una modificación latente y continua de las formas de la vivencia, del pensamiento y de la configuración, ocurre entonces que los nuevos puntos de partida cristalizan en alguna parte, con la figura de un impulso que se destaca como algo nuevo y de una nueva unidad que da forma. En estas ocasiones hablamos de un nuevo estilo generacional, de una nueva entelequia generacional $^{50}$. También aquí hay dos niveles. En primer lugar, se da el caso en que la unidad generacional configura (sencilla e inconscientemente) sus obras y hechos mediante un impulso nuevo que ella misma ha producido; en este caso, la generación sólo sabe intuitivamente de la existencia de una cierta correlación; pero ésta no se eleva aún a la conciencia como una unidad generacional. Decíamos, no obstante, que hay un segundo nivel. Este se alcanza cuando la unidad generacional se torna consciente y se cultiva: como sucede, por ejemplo, en la moderna Jugendbewegung (el «Movimiento de la Juventud») en su desarrollo contemporáneo, o como ya ocurría en cierta medida en su precursora de los primeros años del siglo XIX, la Burschenschaftbewegung (el «movimiento de la corporación de estudiantes»), que daba prueba en muchos aspectos de ese carácter moderno ${ }^{51}(550-551)$.

49) Por su parte, la velocidad de la dinámica social no puede ser causada por el cambio generacional, pues éste permanece siempre constante.

51) En la historia del arte, Pinder tiene una primera orientación; su concepto de entelequia está recogido de las formas artísticas. En una descripción más exacta habría que establecer escalonadamente diferencias entre impulsos generacionales, voluntades embrionarias, tendencias formativas, intenciones de configuración, entelequias, etc. En el presente estadio de la consideración, podemos prescindir de esas diferencias. Por eso, y para simplificar, emplearemos con frecuencia en lo que sigue el término sintético de entelequia que tomamos de Pinder. W. Pinder, Das problem der Generationen in der Kuntgeschichte Europas, Berlín, 1926.

${ }_{51}$ Algunas frases de Herbst pueden demostrar gráficamente el elevado grado de conciencia con que las Burschenschaften («corporaciones de estudiantes») se vivenciaban ya como movimientos juveniles. Las Burschenschaften se sienten continuadoras de las etairiai griegas. Dice Herbst: «Ellos (los griegos) constituían sus etairiai con un sentido análogo al de nuestras Burschenschaften.»V Véase la siguiente frase para caracterizar el temple del movimiento: «... entre nosotros - y creyendo que ya se ha hecho todo-, se deja al joven justamente en la encrucijada cuando se le da la oportunidad de obtener, con alguna erudición, la posibilidad de correr por la vida con poco esfuerzo. Estábamos convencidos de que la vida nos impone elevadas exigencias, y, si esas exigencias no se satisfacían desde arriba, nosotros, confiando en nosotros mismos, creíamos tener derecho 
Es muy significativo el hecho de que las comunidades que se encuentran en situaciones de gran estabilidad, o que al menos experimentan una transformación muy lenta - como la vida campesina-, no conozcan ese fenómeno de las unidades generacionales que se yerguen alimentadas por entelequias completamente nuevas. Tal circunstancia prueba que la aceleración del dinamismo de la sociedad es la ocasión propicia para que se active la potencialidad creativa del nuevo impulso generacional, de ese impulso que duerme en el seno de la posición que ocupa una generación. En esas comunidades de lenta transformación, las nuevas generaciones crecen en medio de continuas modificaciones paulatinas que se producen imperceptiblemente. En ellas se dan en máximo grado esa clase de parecido y esa clase de diferenciación que produce el mero fenómeno de las etapas de la edad; un fenómeno que como hecho vital también permanece constante en la sociedad moderna, y que se puede ver en la atracción que experimentan la juventud por la juventud y la gente de una determinada edad por sus coetáneos. La unidad generacional, entendida en el sentido que hemos descrito, no nacería nunca del mero fenómeno de la mutua atracción vital que se produce entre quienes tienen la misma edad.

Cuanto más acelerado sea el tempo del dinamismo socioespiritual, tantas más oportunidades habrá de que determinadas posiciones generacionales (Generationslagerungen) reaccionen en directo desde su nueva situación generacional (Generationslage) y con una «entelequia» propia frente a las transformaciones. Por otro lado, un tempo excesivamente acelerado puede llevar a que los embriones de las entelequias generacionales se sepulten unos a otros (551-552). Nosotros, que convivimos con fenómenos de ese género, tal vez podamos observar, si lo hacemos con una atención más intensa, que, en sus modos de reacción, los distintos años de nacimiento se suceden unos a otros de forma rigurosamente escalonada ${ }^{52}$, sin que, no obstante, puedan alcanzar la fructífera forma cabal de nuevas entelequias generacionales y principios configuradores, que los erigiría plenamente como tales años de nacimiento diferenciados. Es posible que esas generaciones, que por las razones mencionadas no alcanzan la plena configuración de su entelequia generacional, se enganchen a otras que ya han realizado su formación, o que se vinculen a una generación posterior que sea capaz de una formación más novedosa. Por eso, los sucesos colectivos plenamente decisivos pueden obrar un efecto de «cristalización». $\mathrm{Y}$ es característico de la vida del espíritu que lo que ya está configurado atraiga constantemente a lo potencial, a lo que fluctúa libremente (das Freischwebende). Eso es así aun cuando, en el curso de su insegura configuración por tanteo, el impulso que todavía no está formado haya de diferir en muchos aspectos de su centro de atracción. De este modo, otros impulsos y agitaciones generacionales, previos o posteriores, pueden a menudo $-\mathrm{y}$ a

a ordenar nuestras condiciones de vida de tal modo que pudiéramos formarnos y fortalecernos en ellas de acuerdo con nuestra convicción, aquella que nos habian impuesto la razón y el espíritu del tiempo». F. HERBST, Ideale und Irrtümer des Akademiscben Lebens in unserer Zeit, Stuttgart, 1823, p. 97.

52 Cfr. el artículo de fondo de la Frankfurter Zeitung ya citado. 
causa de la presencia de una forma acuñada por generaciones extrañasquedar ocultos ${ }^{53}$.

A partir de todos esos hechos se infiere que cada posición generacional no tiene por qué corresponderse con una configuración y una tendencia formativa que le sean propias; $y$, también, que la existencia de unas posiciones creadas esencialmente por mediación del ritmo biológico en modo alguno tiene por qué implicar la existencia de una rítmica de las nuevas voluntades generacionales y de los nuevos principios configuradores que se corresponda con ese ritmo biológico. Sin embargo, el intento central de la mayoría de las teorías sobre la generación consiste en establecer - desde una perspectiva naturalista- un paralelismo inmediato entre una rítmica cuantificable de nacimientos decisivos (que determinan en la mayor parte de los casos en intervalos de treinta años) y una rítmica correspondiente del ámbito espiritual. $Y$ es de ese modo como dichas teorías pasan por alto que la activación de la potencialidad dormida en las posiciones generacionales depende de factores extrabiológicos y extravitales, y que, ciertamente, depende en primer plano de la especificidad de la dinámica social, que siempre es singularmente peculiar (552-553). La aparición efectiva de un nuevo estilo generacional con arreglo a un ritmo - ya sea anual, de treinta o cien años, u otro cualquiera - depende de la fuerza desencadenante que tenga el proceso socioespiritual. Un problema específico -que hay que tratar aparte- es el de si ese dinamismo social tiene su componente dominante en la esfera económica o en cualquier otra de las esferas espirituales. Ante todo, hay que decir que es completamente irrelevante la respuesta que haya de darse en cada caso a dicha cuestión. Pero ya se ha dejado constancia aquí de que lo importante es que ese grupo de factores de influencia decide si los nuevos impulsos generacionales pueden condensarse en una unidad formativa, o si han de permanecer en estado latente. La facticidad biológica del cambio generacionah sólo ofrece la posibiliáad de enfrentarse genéricamente con las entelequias generacionales - si no se diese ningún cambio de generación, no conoceríamos el fenómeno de los estilos generacionales-. Sin embargo, la determinación de cuáles vayan a ser las posiciones generacionales que activen su potencialidad depende del plano estructural de la sociedad y del espíritu; un nivel de consideración que es precisamente el que siempre se afana por superar esos planteamientos del problema que una y otra vez oscilan repentinamente entre un naturalismo y un espiritualismo extremos.

Es importante aclarar, desde el punto de vista de la sociología formal, las diferencias entre la posición, la conexión y la unidad de la generación. Tal aclaración resulta ser indispensable para la fundamentación de la problemática,

"La posibilidad de construir entelequias seguramente conecta también con la posibilidad de hacerse valer que tenga en un momento concreto la gente de una edad determinada. Una carta publicada en la Vossiscbe Zeitung (20 de mayo de $1928, \mathrm{n}$. 21 , bajo la rúbrica "Cartas a la Vossische Zeitung») refiere la desfavorable situación que vive actualmente la generación intermedia, es decir, la gente que hoy tiene entre 30 y 50 años. Acerca del prestigio de la edad en las diversas circunstancias, véanse las muy acertadas consideraciones sociológicas de Max WEBER, Wirtschaft und Gesellschaft, p. 609. 
pues sin su ayuda no puede uno hacerse cargo en absoluto de las relaciones dominantes que hay en ella. Es decir, en la medida en que se habla, simplemente y sin mayor diferenciación, de «generaciones» se suelen mezclar constantemente los fenómenos biológico-vitales con los fenómenos correspondientes que forman las fuerzas socioespirituales. Con una mezcla así, se llega a una especie de «sociología de tablas cronológicas» que es capaz de descubrir corrientes espirituales de carácter generacional —que de seguro serán completamente novedosas - gracias a ciertos peritos en historia que se sirven de una «perspectiva de pájaro» para estudiar los momentos históricos necesarios.

Por lo general, Kummer estuvo libre de esos prejuicios. Hablaba de la posibilidad de que en un mismo siglo pudieran coexistir en cualquier momento, frente a la situación, tres, cuatro, cinco generaciones espirituales ${ }^{54}(553-554)$. Creemos que esa dirección de la mirada -que inicialmente era sólo una mirada intuitiva - ha apuntado y nos ha proporcionado la fundamentación que necesitábamos. Sin negar la significación de los datos biológicos, hay que decir que sólo se puede hacer justicia a la problemática global si no se busca en una rítmica aritmética el «llegar a ser» de ésta. Hay que considerar los datos biológicos como los factores de influencia ubicados más profundamente; pero, precisamente por eso, no se debe tratar de captarlos inmediatamente en sus consecuencias manifiestas, sino que es necesario el esfuerzo de observarlos, ante todo, en el elemento de los factores de influencia de carácter socioespiritual.

Parece, pues, que lo propio del proceso histórico es que los factores vitales de influencia que son más elementales operen de modo latente, y que sólo puedan captarse en el elemento propio del plano social y espiritual que está superpuesto a ellos. Expresémoslo de un modo práctico: el investigador sólo puede hacerse cargo de las transformaciones atribuibles al factor generacional, cuando previamente ha distinguido todas las modificaciones atribuibles al

${ }^{54}$ F. Kummer, Deutsche Literaturgeschichte, op. cit., pp. 2 ss. Kummer era periodista y escribió su obra durante su tiempo libre. Accedió al problema de las generaciones a partir de una crítica de las categorías histórico-literarias de «epígono» y de «decadencia». Quiso reemplazarlas por medio de una escala «más natural», y el fundamento que necesitaba para hacerlo lo halló en el fenómeno de la generación. La inspiración se la debía a Erich Scbmidt, quien, juntamente con Haym, Stern y Bartels, dio entrada en la historia de la literatura a ciertas inspiraciones, que palpitaban también en Rümelin y $O$. Lorenz (estos últimos se remontaban a Ranke). En Dilthey el problema aparece por primera vez en 1865, cuando se ocupaba de Novalis. $R$. Haym recibió el concepto de Dilthey cuando, en 1870, compiló su «Romantische Schule» (cfr. F. Kummer, pp. 1 ss., y J. Petersen, p. 133). Ciertamente, la representación de Kummer está concebida a menudo de un modo seco e insuficiente si se la considera desde un punto de vista estético, pero, en ella, el campo visual se ensancha beneficiosamente; afirma en una medida mayor que la usual el despliegue de fuerzas sociales que está detrás de las obras. En ese sentido, resulta satisfactoria la constante consideración que hace de los condicionamientos de la prensa, aun cuando haya que apreciar todo esto únicamente como una manera de empezar muy esquemática. Cfr. O. Lorenz, Die geschichtswissensschaft in Hauptrichtungen und Aufgaben kritisch erörtert, Parte I, Berlín, 1886; Parte II, 1891; J. Petersen, Die Wesensbestimmung der Romantik (cap. VI, «Generation»), Leipzig, 1925, y G. RüELIN, «Über den Begriff und die Dauer einer Generation», Reden und Aufsätze I, Tübingen, 1875 . 
dinamismo histórico-social. Quien se salte esa «esfera intermediaria» estará inclinado a atribuir inmediatamente a un factor natural (generación, raza, situación geográfica, etc.) todos los elementos que se atribuirían a la llamada «influencia del medio», a la «situación del momento».

Lo equivocado de esa búsqueda naturalista no consiste en que acentúe en la vida humana lo natural, sino en que quiere hacerse cargo de lo dinámico de modo inmediato a partir de dichas constantes, y en que pasa por alto y violenta precisamente el estrato intermedio donde realmente nace el dinamismo (554555). Los factores dinámicos operan sobre la base de las constantes - sobre la base de los datos biológicos y antropológicos, etc.-; pero, en cada caso, «procesan» - configuran - de una forma distinta las posibilidades que hay en ellas. Por eso, si verdaderamente se quiere dar cuenta de ellos, hay que indagar en el elemento de ese nivel potencial que se configura sociohistóricamente. Los factores naturales -el cambio generacional también- constituyen el terreno de juego fundamental del acontecer histórico-social. Pero, precisamente porque esos factores naturales son constantes y están por ello siempre presentes, la mudanza no puede clarificarse a partir de dichos factores con la especificidad que le es propia en cada caso. La importancia variable de esos factores naturales (el modo y manera siempre diferentes con que su presencia se procesa) sólo se puede poner de relieve con claridad, precisamente, si se tiene ante los ojos con suficiente nitidez el estrato formativo propio de las fuerzas socioespirituales.

7.

Lo significativo en los estudios sobre las generaciones es que una y otra vez han venido a subrayar el interés teórico por ese factor - un factor indudablemente importante- del acontecer histórico humano. Sin embargo, podemos decir ya, recapitulando, que su unilateralidad estriba en el intento de explicar el dinamismo global del acontecer histórico a partir de ese factor. Se trata de esa unilateralidad que suele ir unida a la alegría del descubrimiento y que, como tal, también es disculpable. Las múltiples teorías de la historia, que últimamente nacen con opulenta abundancia, of recen copiosas pruebas de esa unilateralidad: un momento del acontecer histórico se hipostatiza como factor que soporta el desarrollo de la historia. Las teorías de la raza, las doctrinas sobre las generaciones, el economicismo, las doctrinas sobre el «espíritu del pueblo», etc., todos ellos pecan de tal unilateralidad. Pero tienen, sin duda, el mérito de haber iluminado con mucha intensidad un factor, y de haber mantenido despierto el interés por el problema de los factores estructurales que construyen la historia. De ahí su ventaja frente a una descripción de la historia que se plantee con arreglo a combinaciones causales únicas, o amoldada a configuraciones únicas (555-556). Ese tipo de descripción había reprimido y ocultado el interés por los momentos estructurales que son operativos y, por eso, paulatinamente se hubo de llegar a entender que, puesto que la historia consiste únicamente en 
unicidades, propiamente no se puede aprender de ella. Cualquiera puede ver que eso no es cierto; cualquiera que se permita pensar acerca de la historia y que observe de cerca la vida que vive a diario, puede notar que, en ella, todo nuevo comienzo y toda personalidad extraordinaria sólo obtienen eco en una circunstancia determinada, en un terreno de juego que -incluso cuando se tome como una constante transformación- se puede describir estructuralmente.

Si se quiere representar el dinamismo histórico en su proceso de construcción, y no se quiere atribuir todo a un solo factor, sólo cabe preguntar si no queda ninguna posibilidad de establecer una ordenación de los componentes estructurales de influencia, bien en general, para cualquier época, o bien en particular, para épocas determinadas - puesto que en absoluto se ha dicho que la importancia de las distintas fuerzas sociales y las demás fuerzas que configuran la historia (economía, poder, raza, etc.) permanezca siempre igual-. Evidentemente, no podemos llegar aquí hasta la solución del problema generacional; tan sólo podemos tratar de iluminarlo un poco más al ponerlo en relación con el resto de los factores que construyen la historia.

El mérito de Petersen consiste en haber roto con el monismo al que se había sumado la mayor parte de los tratadistas de las generaciones. Intentó tratar el problema generacional -aplicado al caso concreto de los románticos- en conexión con los restantes factores históricos (progenie, territorialidad, «espíritu del pueblo», sociedad, etc.).

Pero por muy satisfactoria que sea la ruptura con esa teoría monista, tampoco nos basta con determinar una mera yuxtaposición de factores que, como es evidente, sólo podría ser provisional. También el tratamiento del factor social debe dejar al sociólogo insatisfecho.

Al hablar de «espíritu del tiempo» es necesario notar, con la misma precisión empleada frente al resto de los factores, que el «espíritu del tiempo» no es siempre el espíritu de toda la época (556-557). Sucede más bien que, en la mayoría de los casos, el principal objeto de atención y de conversación se asienta en un estrato que adquiere (ya sea conjuntamente con otros o por separado) una significación especial en un momento determinado y que imprime también su impronta espiritual sobre el resto de las corrientes, sin destruirlas ni absorberlas.

Pero la descomposición del concepto de «espíritu del tiempo» se puede abordar desde un lado distinto del que eligió Pinder. En su planteamiento, la unicidad de la construcción «espíritu del tiempo» se disuelve en favor de la realidad de las entelequias generacionales. El «espíritu del tiempo» no es - según él- unitario, puesto que no se corresponde con ninguna entelequia unitaria y real. También nosotros podemos negar la existencia de esa entelequia del «espíritu del tiempo» y negar a la vez que se dé una unidad del espíritu de una época que derivaría de dicha entelequia; pero entendemos, en cambio, que esa relativización tiene que ejecutarse — de entrada y primordialmenteen favor de las entelequias de las corrientes, que son las que tensan polarmente las distintas unidades temporales. 
El siglo XIX no tenía ningún «espíritu del tiempo». Ocurría, más bien, que su unidad era esencialmente el resultado (si es que queremos hacer referencia al ámbito político) ${ }^{55}$ de la lucha recíproca entre el impulso tradicional-conservador y el liberal -a los que después se unió el impulso socialista-proletario.

En todo caso, no queremos ir tan lejos como Pinder en la destrucción de ese concepto (557-558). Niega éste que en la unidad temporal se pueda ver en su esencia el entrecruzamiento eventual, contingente, de las demás entelequias (ifalsos acordes!). El «espíritu del tiempo» se da unitariamente en la medida en que es posible entenderlo en un sentido dinámico-antinómico (y el propio concepto tiene sentido como una construcción correspondiente a tal fenómeno).

Veamos en qué consiste la unidad dinámico-antinómica de una época; es decir, veamos cuándo se puede afirmar que las polaridades que están presentes en el seno de una época se orientan constantemente unas respecto a las otras, y cuándo empiezan a ser comprensibles los distintos puntos de vista. Pues bien, esto ocurre cuando somos capaces de entender las posiciones polares como distintos intentos de dominar un mismo destino y la problemática social y espiritual correspondiente ${ }^{56}$. No se trata simplemente de un cúmulo casual de entelequias que coexisten temporalmente (como lo entiende Pinder), ni tampoco de una entelequia independiente (de un «centro unitario de la voluntad», de un «principio formativo», como pensaba Petersen), que se realiza como algo nuevo e independiente con respecto a las demás entelequias. Se trata más bien de una tercera alternativa: de una relación de tensión dinámica, que puede ser comprendida como tal en su especificidad, pero que de ninguna manera puede ser sustantivada.

Las verdaderas entelequias se dejan ver en primer lugar en las ya mencionadas corrientes. Cada una de esas polaridades fundamentales de las que hemos hablado - que se explican bien desde la estructura social-forma,

55 Tomamos intencionadamente nuestros ejemplos del ámbito de la historia de las ideas políticas. Lo hacemos, por un lado, para contrapesar la unilateralidad de la mayoría de las teorías de las generaciones, que se orientan (especialmente en Alemania) hacia la historia de la literatura o del arte. Y también, en segundo lugar, porque nos parece que, de esta forma, tanto la situación estructural de los impulsos que impelen socialmente como la diferenciación de las generaciones van a poderse reflejar aquí de la manera más clara. En nuestra opinión, el resto de las entelequias, de los cambios de estilo, tienen que ser investigados por sí mismos. Las entelequias de la historia del arte y de la historia de la literatura no pueden derivarse de lo político de ningún modo; pero, partiendo de esa instancia, su conexión recíproca y sus afinidades pueden captarse y ponerse de relieve. Realmente, el artista vive en primer plano en su propio mundo artístico y en sus respectivas tradiciones; pero, en cuanto hombre — por muy indiferente que pueda resultatle la política-, siempre está vinculado con las fuerzas sociales que impulsan a su generación. $Y$, a partir de esa vinculación, el artista transforma las voluntades y entelequias que se dan en el ámbito de lo puramente artístico. Nos parece que la historia de las ideas políticas es importante, en primer lugar, como centro de orientación para obtener la visión general de la contextura global. Más abajo continuaremos hablando de esto.

56 Entendemos el «espíritu del tiempo» como la concatenación continua y dinámica de las «conexiones generacionales» que se suceden entre sí. 
desde ella misma, intenciones básicas específicas. Dichas intenciones básicas están presentes en los espacios sociales como principios formativos durables (aun cuando se transformen constantemente) más allá de los cambios generacionales. $\mathrm{Y}$ es entonces, en el seno de esas entelequias abarcantes y duraderas de las corrientes, donde las nuevas unidades generacionales que logran hacerse valer construyen sus entelequias de generación, con las que, a su vez, transforman las entelequias de corrientes como la liberal, la conservadora y la socialista. Por eso, puede decirse que las unidades generacionales realmente no son formas ya acabadas de construir: aun cuando irradien sus propias entelequias, éstas no son en absoluto comprensibles por sí mismas, sino que sólo se pueden captar en el elemento propio de las entelequias de las corrientes. Por esa misma razón, se puede añadir que las generaciones espirituales, las unidades generacionales, no pueden en absoluto delimitarse o fijarse si no es dentro de corrientes específicas (558-559). Una entelequia de corriente precede a la entelequia generacional. Sólo dentro de aquélla puede ser ésta reconocida y diferenciada. No queremos decir con eso que siempre que haya, en un momento dado, corrientes que luchan entre sí, tengan que erigirse nuevas entelequias generacionales.

Así, en la primera década del siglo XIX, por ejemplo, no es que se diera sólo una generación romántico-conservadora ${ }^{57}$, a la que sucedió una generación liberal-racionalista (la junge Deutschland, etc.). A la vista está que, durante los primeros años de ese siglo, sólo la juventud que conducía sus vivencias según el polo romántico-conservador consiguió asentar nuevas entelequias generacionales en el mundo. Unicamente esa porción de la juventud acertó a dejar su impronta ampliamente sobre la determinación básica de la época. No es que en los años treinta surgiera una «nueva generación» que, de repente, volvió a ser liberalracionalista, sino que los jóvenes que estaban en la línea liberal-romántica consiguieron entonces, por primera vez, reformar con arreglo a su propia generación la tradición de la que procedían. Las polaridades básicas estuvieron siempre ahí. Pero la posibilidad de formación creativa se produjo una vez en favor del polo romántico-conservador y otra en favor del liberal-racionalista.

Se habla -ése es el caso de Petersen ${ }^{58}$ - de diferentes tipos generacionales: dirigentes, adaptados y oprimidos. De ese modo, se apunta algo que es correcto e importante, pero que nunca acaba de precisarse, debido a una falta de diferenciación conceptual desde el punto de vista sociológico.

Para Petersen, los tipos de carácter — que son de orden transtemporal- y el «espíritu del tiempo» (a este último lo presenta como una magnitud unívoca y determinable) están inmediatamente relacionados entre sí, como si de hecho ambos factores luchasen en la vida histórica, y como si el destino de los individuos particulares estuviese siempre condicionado por la mutua compenetración de esos dos componentes (559-560). Fijemos la atención en uno de los tipos

${ }^{7}$ Por lo demás, lo romántico y el conservadurismo no convergen desde el principio. En Alemania, como ocurrió en Francia, el movimiento romántico fue originariamente un movimiento revolucionario.

${ }^{58}$ Cfr. J. PetLrsen, Die Wesensbestimmung der Romantik, op. cit., pp. 146 ss. 
emocionales de Petersen en particular, aquel que él considera «de índole romántica», y supongamos que ese tipo de carácter emocional vive en una época cuyo «espíritu del tiempo» es romántico. Pues bien, en ese caso, se producirá un refuerzo de la predisposición del individuo en cuestión como resultado de su encuentro con esas circunstancias y, de ese modo, dicho individuo se convierte en esa época en «tipo generacional dirigente». En las mismas circunstancias, otro individuo cuya predisposición esté primordialmente en equilibrio entre lo emocional y lo racional puede verse atraído hacia la posición romántica. De esa forma proporcionaría el «tipo adaptado» de Petersen. Tomemos, finalmente, a un tercer individuo cuya índole primordial sea racionalista. Pues bien, en el seno de una época romántica, éste daría el «tipo generacional oprimido». Porque a ese individuo sólo le quedan dos posibilidades: que su propia índole ceda, siguiendo la moda, ante el «espíritu del tiempo», lo cual conduce a la esterilidad; o bien que persista tenazmente en su postura básica, para ser, entonces, un solitario en su propio tiempo. Como tal, será bien un epígono de los antecesores, o bien un precursor de una generación futura.

Si de entrada alcanzamos a ver que la equiparación entre lo «emocional» y la «índole romántica», etc., resulta ser un tanto esquemática, puede verse enseguida, en cambio, que algo más correcta es, ciertamente, la distinción entre los tipos dirigente, adaptado y oprimido. Lo que ocurre no es sólo que esas predisposiciones de carácter transtemporal se enfrentan en los espacios sociales con un «espíritu del tiempo» unitario e indiferenciado (que en realidad no existe como tal en absoluto). El individuo particular se forma, ante todo, con las influencias y las corrientes espirituales contemporáneas, que moran precisamente en aquellos círculos vitales con los que hay que contar desde un punto de vista sociológico. Esto quiere decir, para empezar, que al individuo no le afecta ni le atrae en absoluto la globalidad del «espíritu del tiempo», sino sólo aquellas corrientes de su tiempo que, tanto tradicional como actualmente, están presentes en su entorno (560-561). Pero el hecho de que se hayan establecido precisamente esas corrientes y no otras en los círculos vitales de ese individuo, y que actualmente se mantengan, se basa esencialmente en otra condición; se fundamenta en el hecho de que las oportunidades típicas de esa situación vital - en la que existen tanto él como su entorno- encuentran adecuada expresión, precisamente, en esos modos de comportamiento. Por lo tanto, lo que fomenta y frena al individuo particular y a su índole primordial no es de ninguna manera un «espíritu del tiempo» unitario e indiferenciado. Se trata, en cambio, siempre, in concreto, de una polaridad determinada, de una polaridad del «espíritu del tiempo» que se ha depositado en el círculo del individuo en cuestión. La índole propia del carácter de tal individuo se explica, en primer término, con esa corriente específica.

Hay hechos que el historiador de la literatura parece estar inclinado a pasar por alto. En primer lugar, que la mayoría de los hombres pertenece a una determinada corriente de su tiempo; en segundo lugar, que el «espíritu 
del tiempo»se presenta siempre fraccionado, y que no ocurre, por ejemplo, que de pronto venga a ser un tiempo exclusivamente romántico. Y si el historiador no advierte esos hechos es debido a que orienta primariamente su atención hacia el destino de los literatos y, por consiguiente, hacia el destino de un estrato completamente específico.

Sólo el estrato literario, que en nuestra sociedad está en una relativa situación de libre fluctuación social (se sobreentiende que ésta también es una característica sociológica), tiene la posibilidad de cambiar de adhesión. Según las circunstancias, se adherirá bien a ésta, bien a aquella corriente. En la primera mitad del siglo XIX, dicho estrato se adhirió siempre ampliamente a la corriente de la nueva generación, una generación que estaba amparada por las circunstancias y que era a la sazón virulenta; o sea, a una corriente en la que siempre fue posible la formación de entelequias generacionales. La época de la Restauración y la debilidad social y política que caracterizaba a la burguesía alemana de comienzos del siglo xIx favorecieron por vez primera la formación de entelequias en el polo romántico-conservador de la juventud. Ese polo atrajo a una gran parte de ese estrato literario que estaba en situación de libre fluctuación. A partir de los años treinta, la Revolución de Julio y la industrialización - que estaba en pleno crecimiento- favorecieron el advenimiento virulento de nuevas entelequias liberal-racionalistas en el seno de la generación que las sustentaba: a una gran parte de los literatos había que encontrarlos en ese momento en la cantera liberal-racionalista (561-562).

Si se atiende a ese desarrollo y se dedica atención preferente a ese estrato literario, parece, por una parte, como si en un momento determinado se diera únicamente un «espíritu del tiempo» romántico y más tarde otro privativamente racionalista. Pero es que entonces se tiene, además, la impresión de que tales literatos, poetas y pensadores son quienes determinan de forma exclusiva el «espíritu del tiempo». Bien distinto es lo que ocurre en realidad. Las voluntades que son decisivas - aquellas que determinan la dirección de las cosas- no están cimentadas precisamente en ese estrato que venimos mencionando, sino en otro mucho más compacto que está detrás de él. Se cimentan en el fraccionamiento polar de los sustentadores sociales, que, en cuanto tales, están siempre presentes. El oleaje que el avance de las corrientes particulares causa en el «espíritu del tiempo» sólo se produce cuando, en el curso de las circunstancias temporales, uno $u$ otro polo -ora éste, ora aquél- es capaz de orientar a una generación que deviene activa y que arrastra consigo no sólo los «estratos medios», sino especialmente a aquel estrato literario que está en situación de libre fluctuación social. De todos modos, aun así, no arrojamos suficientemente luz sobre la enorme significación que tiene ese estrato literario (donde con frecuencia hay que contar a los más poderosos pensadores y poetas); porque son precisamente sus miembros quienes de verdad dan forma y profundidad a todas las entelequias, las cuales irradian de ese modo desde todos los espacios sociales. No obstante, cuando nos orientamos exclusivamente en atención a ellos, no tenemos plenamente en cuenta esa estructura de 
corriente que es propia de los movimientos espirituales. Cuando se trae a colación toda la corriente histórico-social, no hay época alguna que sea exclusivamente romántica o exclusivamente racionalista. Tal polaridad está univocamente presente, por lo menos, desde el siglo XIX; y bien cabe decir que en cierto momento una $\mathrm{u}$ otra de las direcciones toma el mando, se hace dominante. Resumámoslo de nuevo: desde el punto de vista sociológico, esto significa tanto como decir que en circunstancias favorables se hace posible (ya sea en este polo, ya sea en aquél) la construcción de la entelequia de una generación; con ella se revisten siempre en primer lugar los oscilantes estratos medios, pero también con ella se viste el estrato de los literatos. De ahí se deriva que el hombre que está firmemente enclavado en su sociedad — sea cual sea el «tipo de alma» al que pueda corresponder- se enfrenta primariamente a aquella corriente que domina en su círculo vital (562-563); en cambio, el literato que fluctúa libremente — sin que tampoco importe en este caso cuál sea su «tipo de alma» - tiene que habérselas principalmente con las corrientes contemporáneas dominantes. Con seguridad, varía de un caso a otro el modo concreto que cada individuo particular tenga de resolver esa lucha tripartita entre su propia índole, la postura espiritual que sea socialmente más acorde con ella y, por último, la corriente que asciende hasta llegar a ser la dominante en esa época concreta. Sólo una personalidad muy poderosa puede ser capaz de mantener firme la predisposición que es propia de su carácter personal frente a la postura espiritual polarmente orientada que está presente en su propio círculo vital (y muy especialmente cuando se considera que tal postura está en alza). Era difícil que un «burgués» del primer cuarto del siglo XIX que tuviera inclinación irracionalista fuese capaz de llegar a ser «para sí». Pero tan penoso como eso tuvo que ser, para los nobles de inclinación racionalista de la nueva generación, perseverar en su postura en contra de un romanticismo y una religiosidad que estaban en ascenso. En tales casos, mucha gente, que por su antigua posición generacional no puede o no quiere vivir con arreglo a la nueva entelequia generacional que se alza en sus círculos de vida social, se encuentra al abrigo del surgimiento virulento de la nueva entelequia generacional -así, Federico Guillermo III y su séquito, que en muchos casos se habían criado en la ortodoxia racionalista, pero también en la vieja forma del conservadurismo, pudieron sustraerse a la nueva ola religiosa, romántica y pietista; por el contrario, su hijo, el príncipe heredero, que más tarde llegaría a ser Federico Guillermo IV, fue la más característica expresión de esa corriente-. Todo esto ilumina desde otro ángulo, y con mayor claridad, el hecho de que la influencia de los factores generacionales no se puede experimentar inmediata y directamente, sino que se recibe en el propio elemento del acontecer sociohistórico.

La posición generacional está siempre presente como posibilidad. Trata constantemente de realizarse, pero no en el elemento del «espíritu del tiempo» en general, sino siempre en las corrientes concretas que en cada caso existen ${ }^{59}$

59 Esto se puede observar también en la moderna Jugendbewegung, que constantemente vuelve a polarizarse social y políticamente. Como manifestación coherente que es, da 
(563-564). Como hemos visto, depende del destino histórico que la tendencia hacia la construcción de entelequias generacionales que existe en el seno de esas corrientes baste para su realización, y también depende de él cuál vaya a ser finalmente el polo concreto en que dicha tendencia tenga éxito.

A esos factores de la problemática generacional, que son suficientemente complicados por sí mismos, se agrega aún otro que en las reflexiones anteriores no se ha tenido en cuenta.

Todavía no hemos considerado que la entelequia generacional que está abriéndose camino no tiene la misma posibilidad de abrirlo en todos los ámbitos, en todas las esferas del espiritu. Las esferas particulares pueden, en cada ocasión, servir para fomentar u obstaculizar el proceso por el que la entelequia generacional se manifiesta. En este caso, se puede hablar con toda seguridad de una gradación de las esferas particulares según el significado documental que tengan para la entelequia generacional.

Se percibe así, con toda claridad, que las ciencias exactas - que tan reducida importancia conceden a la concepción del mundo- ocultan ampliamente las entelequias generacionales.

En general, «la esfera de la civilización» ${ }^{60}$, con su estructura rectilínea de desarrollo, oculta mucho más que la esfera de la cultura las transformaciones vivenciales y voluntarias que tras ella ocurren. Y Pinder seguramente tenía razón cuando, dentro de la propia esfera cultural, atribuía a las documentaciones verbales (religión, filosofía, poesía, ciencia) un papel diferente al de las artes plásticas y al de la música ${ }^{6}$.

También aquí habrá que distinguir con mayor precisión. La pregunta que habría que hacer para seguir adelante plantea el problema de hasta qué punto los varios impulsos de las corrientes y de las generaciones y los principios formativos presentan una afinidad con determinados «géneros», y si acaso no acuñan ellos mismos géneros nuevos. En ese caso, la generación romántica habría acuñado y cultivado géneros completamente distintos que los liberales de la generación anterior a la revolución de marzo de 1848 .

Asimismo, hay que traer a consideración el valor documental ${ }^{62}$ que puedan

prueba del fenómeno de la «conexión generacional». Pero sólo se puede comprender concretamente a partir de la configuración de «unidades generacionales» sociales y espirituales que se diferencian entre sí.

${ }^{6}$ Cfr. ese término en Alfred Weber, Prinzipielles zur Kultursoziologie, en Arcbiv für Sozialwissensschaft und Sozialpolitik, 47, 1921.

61 Cfr. Pinder, Das problem der Generationen in der Kuntgescbichte Europas, op. cit., 156.

62 Nota del traductor: La noción de sentido (o significado) documental que emplea Mannheim procede de la sociología de la cultura de Alfred Weber (quien entendía el «proceso cultural» como la sucesión de las obras en las que un pueblo documenta - evidencia documentalmente- - su ser, como la serie de símbolos en los que se revela su esencia anímica). Mannheim la explica en su ensayo sobre la interpretación de las concepciones del mundo. Se trataría de un tercer estrato de sentido propio de las manifestaciones culturales de la vida humana, que, como ocurre con el «sentido expresivo», se superpone al mero «sentido objetivo» de éstas. El estrato documental del sentido (die dokumentarische Sinnscbicbt) sería, en todo caso, el plano semántico principal -el nexo 
tener las diversas formas de convivencia social (564-565). Existen también en este punto varias formas de reunión, que pueden ser más adecuadas para las distintas intenciones de las corrientes o de las generaciones. Ya Mentrét ${ }^{3}$ había llamado la atención hacia el hecho de que la adhesión que se establece por medio de estatutos es un reflejo mucho menos apropiado de los nuevos impulsos generacionales que las formas previas, más fluidas, de socialización (como los salones $)^{\text {th }}$.

Lo que esto prueba es que, así como no se puede determinar terminantemente y de antemano si los planos sociales y espirituales pueden servir de fomento o de obstáculo para que la entelequia generacional se manifieste, tampoco cabe hacerlo en relación con las «esferas» en las que dicha entelequia puede encontrar expresión con mayor rapidez. Se confirma así, ahora desde otro punto de vista, que precisamente es el factor generacional - un factor que está presente y opera en directo con la regularidad de las leyes naturales- el factor más difícil de comprender, y que sólo puede ser comprendido mediante un rodeo por el ámbito socioespiritual.

El fenómeno generacional es uno de los factores básicos en la realización del dinamismo histórico. El estudio del funcionamiento combinado de las fuerzas que operan conjuntamente es de por sí un conjunto problemático unitario sin cuya aclaración no es posible comprender la historia en su devenir. Una cuestión como ésa únicamente se puede resolver mediante un análisis previo y minucioso de la especificidad de los componentes que en este caso son relevantes.

El análisis del fenómeno generacional desde la sociología formal puede ayudar en ese sentido, puesto que muestra claramente lo que se puede explicar

global de sentido- al que se refiere la tarea hermenéutica de las ciencias humanas, y, desde luego, la de la propia sociología. Es, por consiguiente, el único estrato propiamente significativo, pues comprende el contexto global de la Weltanschauung, que es el marco inexcusable para la comprensión del carácter, del ser sustancial de los sujetos a partir de sus acciones y creaciones culturales. Hay que tener en cuenta, no obstante, que en escritos posteriores, como los Ensayos de Sociología de la Cultura, Mannheim llama «significado objetivo» a ese «significado documental» del que estamos tratando, subrayando todavía más el carácter social del significado. Véanse K. ManNHeIm, «Beiträge zur Theorie der Weltanschauungs-Interpretation» (1921-1922), en K. Mannheim, Wissenssoziologie, Kurt H. Wolf (ed.), Neuwied, Luchterhand, 1970, pp. 91-154; está traducido al inglés como «On the Interpretation of Weltanschauung», en K. MANNHEIM, Essays on the Sociology of Knowledge, Paul Kecskemeti (ed.), Londres, Routledge and Kegan Paul, 1952, pp. 33-83; y «Hacia una sociología del espíritu», en K. Mannieim, Ensayos de sociología de la cultura, Madrid, Aguilar, 1963, traducido del inglés por Manuel Suárez (2." ed.; la primera, de 1957), pp. 33-134. Para la localización del asunto en la obra de A. Weber puede consultarse su libro Prinzipien der Geschichts und Kultursoziologie, Munich, R. Piper \& Co. Verlag, 1951. Existe versión española de J. M. Coco Ferraris, Sociología de la bistoria y de la cultura, Buenos Aires, Galatea-Nueva Visión, 1957.

${ }^{63}$ F. MENTRE, Les générations sociales, op. cit.

ot Scbmoller habla sobre la específica forma de la lucha entre los jóvenes y los mayores en los años cincuenta en su Grundriß der allgemeinen Volkswirtschaftslebre, München und Leipzig, 1923, II, p. 591. 
desde ese componente y lo que no puede entenderse de forma inmediata a partir de él.

\section{BIBLIOGRAFIA ${ }^{65}$}

Acinthon: Les jeunes gens d'aujord'oui, París, Plon Nourrit, 1912.

Ageorges: La marche montante d'une génération (1890-1910), 1912.

BaInville: Histoire de trois générations.

BoLl, F.: Die Lebensalter. Ein Beitrag zur antiken Ethnologie und zur Geschichte der Zablen, Berlín, 1913.

Brinckmann, A. E.: Spätwerke grosser Meister, Frankfurt, 1925.

COURnot, A.: Considérations, 1872.

Curtius, E. R.: Die literarischen Wegbereiter des neuen Frankreichs, Postdam.

Dilthey, W.: «Über das Studium der Geschichte der Wischenschaften vom Menschen, der Gessellschaft und der Staat» (1875), Gesammelte Scbreiften, V, pp. 36-41.

- Leben Schleiermachers, I, 2, Aufl Berlin, Leipzig, 1922.

DROMEL, Justin: La loi des révolutions, les générations, les nationalités, les dynasties, les réligions, Didier \& Co., 1962.

*Espinas: Les sociétés animales, París, 1877.

Ferrari, G.: Teoria dei periodi politici, Milano, Hoepli, 1974.

Giese: «Erlebnis des Alters», Deutsche Psychologie, 5, 2, Halle, 1928.

Grimm, J.: Über das Alter, Reclams Universal Bibl., n." 5311.

HeIdegger, M.: Sein und Zeit, Jabrbucb für Philosophie und phänomenologische Forschung, Halle, 1927 , pp. 384 ss.

Herbst, F.: Ideale und Irrtümer des Akademiscen Lebens in unserer Zeit, Stuttgart, 1823. Honigsheim, P.: «Die Pubertät», Kölner Vierteljabreshefte für Soziologie, III (1924), 4.

JoEl, K.: «Der sekuläre Rhythmus der Geschichte», Jahrbuch für Soziologie, 1 (1925), Karlsruhe.

Korschelt, E.: Lebensdauer, Altern und Tod, 3. ${ }^{a}$ ed., 1924 (Bibliogr.).

Kummer, F.: Deutsche Literaturgeschichte des 19. Jabrbunderts. Darsgestellt nach Generationen, Dresden, 1900.

LANDSBER(iER, Franz: «Das Generationsproblem in der Kuntsgeschichte», Kritische Berichte (anuario), 1927, n. ${ }^{\circ} 2$.

LORENZ, O.: Die geschichtswissensschaft in Hauptrichtungen und Aufgaben kritisch erörtert, Parte I, Berlín, 1886; Parte II, 1891.

*Mannheim, K.: «Das Konservative Denken», Archiv für Sozial Wissenschaft und Sozialpolitik (1927), 57, 1, pp. 68-142; 57, 2, pp. 470-495.

- «Beiträge zur Theorie der Weltanschauungs-Interpretation», Jabrbuch für Kunstgescbichte, I (Wien, 1923). Publicado también en la serie «Kuntstgeschichtliche Einzeldarstellungen», II, compilación del «Kunsthis. Institut des Bundes denkmalamtes», Wien, 1923 , pp. 38 ss.

"MARX: Revolution und Kontre-Revolution in Deutschland, Stuttgart, 1913 (3." ed.), pp. 20 ss.

${ }^{65}$ Nota del traductor: Esta es la bibliografía aducida por Mannheim en el texto, que apenas ha sido retocada con respecto a las recogidas en la compilación inglesa o alemana. Las publicaciones que aparecen señaladas con un asterisco las citaba Mannheim en las notas, pero no habían sido incluidas en la bibliografía, bien por su inespecificidad o por tratarse de bibliografía secundaria a la que remitía alguno de los autores citados. De hecho, en la versión original, el apartado bibliográfico había sido titulado como una contribución «Para una bibliografía sobre el problema generacional. Teoría y práctica». Como puede comprobarse, el propio autor señala en las notas cuáles de estas obras contienen referencias bibliográficas valiosas. 
*Meillet, A.: Methode dans les sciences, París, Alcan, 1911.

*-Introduction à l'étude comparative des langues indo-européennes, 1903.

Mentre, F.: Les générations sociales, París, Ed. Bossard, 1920.

NoHL, H.: «Das Verhältnis der Generationen in der Pädagogik», Die Tat (semanario), mayo 1914.

Ortega y Gasset, J.: Die Aufgabe unserer Zeit, Introducción de E. R. Curtius, Zurich, Neuen Schweizez Runschau (Cap. I, «Der Begriff der Generation»), 1928.

Petersen: Die Wesensbestimmung der Romantik (Cap. VI, «Generation»), Leipzig, 1925.

PINDER, W.: Kuntgeschicbte nach Generationen. Zwischen Pbilosopbie und Kunst, Johann Volkelt zum 100 Lehrsemester dargebracht, Leipzig, 1925.

- Das problem der Generationen in der Kuntgescbicbte Europas, Berlín, 1926.

PlatZ, R.: Geistige Kämpfe in modernen Frankreicht, Kempten, 1922.

Rumelin: «Über den Begriff und die Dauer einer Generation», Reden und Aufsätze, I, Tübingen, 1875 .

SCHERER, W.: Geschichte der deutschen Literatur, 3.* ed., Berlín, 1885.

*SCHMOLLER: Grundriß der allgemeinen Volkswirtschaftslehre, München und Leipzig, 1923, II.

Schurtz, H.: Altersklassen und Männerbünde. Eine Darstellung der Grund formen der Gesellschaft, Berlín, 1902.

SPRANGer: Psychologie der Jugendalters, Leipzig, 1925.

VAloIs, G.: D'un siècle à l'autre. Chronique d'une génération (1885-1920), París, Nouvelle Librairie Nationale, 1921.

"Weber, A.: Principielles zur Kultursoziologie, Archiv für Sozialwissensschaft und Sozialpolitik, 47, 1921, pp. 1-49.

"Weber, M.: Wirtscbaft und Gesellschaft. Grundriss der Verstebende Soziologie, Tübingen, J. C. B. Mohr, 1922.

WIESE, L. von: Allgemeine Soziologie als Lebre von den Beziebungsgebilden (Teil I: «Beziehungslehre»), München und Leipzig, 1924.

- «Väter und Söhne», Der neue Strom (anuario), 1, n." 3.

ZEUTHEN, H. G.: «Quelques traits de la propagation de la science de génération en génération», Rivista di Scienza, 1909.

(Traducción de Ignacio SÁNCHEZ de la YnCERA.) 


\section{REFERENCIAS BIBLIOGRAFICAS}

